\title{
Numerical and experimental studies of a capillary-tube embedded PCM component for improving indoor thermal environment
}

Article

Accepted Version

Creative Commons: Attribution-Noncommercial-No Derivative Works 4.0

Jobli, M. I., Yao, R., Luo, Z., Shahrestani, M., Li, N. and Liu, H. (2019) Numerical and experimental studies of a capillary-tube embedded PCM component for improving indoor thermal environment. Applied Thermal Engineering, 148. pp. 466-477. ISSN 1359-4311 doi:

https://doi.org/10.1016/j.applthermaleng.2018.10.041

Available at https://centaur.reading.ac.uk/81252/

It is advisable to refer to the publisher's version if you intend to cite from the work. See Guidance on citing.

To link to this article DOI: http://dx.doi.org/10.1016/j.applthermaleng.2018.10.041

Publisher: Elsevier

All outputs in CentAUR are protected by Intellectual Property Rights law, including copyright law. Copyright and IPR is retained by the creators or other copyright holders. Terms and conditions for use of this material are defined in the End User Agreement. 


\section{CentAUR}

Central Archive at the University of Reading

Reading's research outputs online 


\title{
Numerical and experimental studies of a Capillary-Tube embedded PCM component for improving indoor thermal environment
}

\author{
Mohamad Iskandar Bin Jobli ${ }^{1,2 *}$, Runming Yao ${ }^{1 *}$, Zhiwen Luo ${ }^{1}$, Mehdi Shahrestani ${ }^{1}$, Nan \\ $\mathrm{Li}^{3}$ and Hong $\mathrm{Liu}^{3}$
}

${ }^{1}$ School of the Built Environment, University of Reading, RG6 6DF, Reading,UK.

${ }^{2}$ Department of Mechanical and Manufacturing Engineering, UNIMAS, 94300 Kota Samarahan, Sarawak, Malaysia.

${ }^{3}$ Joint International Research Laboratory of Green Buildings and Built Environments (Ministry of Education), Chongqing University, Chongqing 400045, China

*Corresponding emails:M.I.B.Jobli@pgr.reading.ac.uk; r.yao@reading.ac.uk

\begin{abstract}
:
This paper aims to analyse the thermal characteristics of a novel system of Capillary Tubes embedded in a Phase Change Material (CT-PCM) as part of active building environmental design for energy conservation and the improvement of indoor thermal environment. The CT-PCM system is proposed based on the concept that low-grade energy utilisation potential could be harnessed and maximised by buildings' radiant heating/cooling systems and phase change material. The CT-PCM component is first built in the laboratory, and the thermal characteristics of the CT-PCM are investigated through a set of thermal response experiments. In addition, a simplified model is developed to assess the longterm thermal performance of the CT-PCM system for its application during a strategical system design stage. To ensure the robustness of the numerical model in the assessment of the thermal performance of the system, the developed model is evaluated against the experiments under a set of dynamic thermal boundary conditions. The evaluation process reveals that when the flow rate of thermal fluids in the CT-PCM system is more than $800 \mathrm{ml} / \mathrm{min}$, the simulation results of the proposed simplified model are in a good agreement with the experiment. When the flow rate in the capillary tube is smaller than $800 \mathrm{ml} / \mathrm{min}$, the correction factors are derived to address the non-uniformity of temperature distribution.
\end{abstract}


Keywords: PCM, hydronic radiant system, low grade energy, capillary tube, building energy saving

\begin{tabular}{|c|c|c|c|}
\hline \multicolumn{4}{|c|}{ Nomenclature } \\
\hline$K$ & $\begin{array}{l}\text { material thermal conductivity } \\
\left(\mathrm{W} / \mathrm{m}^{\circ} . \mathrm{C}\right)\end{array}$ & $L$ & PCM latent heat $(\mathrm{J} / \mathrm{kg})$ \\
\hline$O$ & heat generation rate per area & $H$ & enthalpy $(\mathrm{J} / \mathrm{kg})$ \\
\hline & $\left(\mathrm{W} / \mathrm{m}^{2}\right)$ & $m_{\mathrm{w}}$ & $\begin{array}{l}\text { mass flow rate of water } \\
(\mathrm{kg} / \mathrm{s})\end{array}$ \\
\hline$T$ & local temperature $\left({ }^{o} \mathrm{C}\right)$ & & 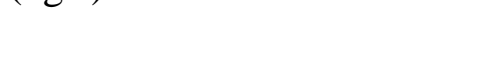 \\
\hline$\rho$ & material density $\left(\mathrm{kg} / \mathrm{m}^{3}\right)$. & $c_{\mathrm{pw}}$ & $\begin{array}{l}\text { specific heat of water } \\
(\mathrm{J} / \mathrm{kg} \cdot \mathrm{k})\end{array}$ \\
\hline$T_{\mathrm{w}}$ & water temperature $\left({ }^{\circ} \mathrm{C}\right)$ & $A$ & overall area of capillary mat \\
\hline
\end{tabular}

\section{Introduction}

The application of active radiant systems for heating in winter and cooling in summer has expanded in recent years [1][2]. In some cases, radiant cooling/heating systems could potentially save up to $30 \%$ of the energy consumption comparing with traditional convective heating/cooling systems [3][4]. Construction of an active system may consist of pipes/tubes embedded in concrete slabs/floors/roofs where heat is allowed to exchange with the surrounding and the fluid. One example of an active radiant heating system is the Thermally Activated Building System (TABS) [5]. TABS utilises a water piping system embedded in building structures to store thermal energy. The heat stored in building structures (slabs/concretes) carried by the water will then exchange heat passively to enhance indoor thermal comfort. TABS with high thermal inertia is well-known for its peak load shifting ability as well as operating on low cost periods [6][7]. This helps to prolong the intermittent availability of renewables such as night-time cooling and solar radiation when these sources are no longer available [8]. Up to $30 \%$ of improvement in energy efficiency was reported when a system comprised of pipe-embedded roof/wall is coupled with low-grade energy [9]. One downside to the application of TABS is that it requires massive building structure (thermal mass) for thermal storage. For the system to work effectively, it requires high thermal mass to store or release adequate heat from the slabs particularly for peak load shifting [10]. Unless huge space requirement is provided, it is a burden for its application in new or existing buildings. This deficit can be overcome with the introduction of PCM to replace the massive building structures as PCM is known with its high thermal mass for its volume. 
PCM has been used passively to control indoor thermal environment through thermal buffering [11][12]. Passive PCM is mainly used for peak load shifting in building sector [13][14]. Passive PCM has also been used to replace heavier and bulkier building components as it has high thermal mass over its volume which means lighter building components can be developed with PCM while maintaining its thermal mass [15]. While PCM on its own has gained reputation as part of building components, there are few notable drawbacks including limited thermal storage, low thermal conductivity and high initial cost of PCM [16][17]. Further application of passive PCM is restricted by these limitations. Integration of active building environmental systems and PCM which is known as active PCM or thermally activated PCM [15] can be used to uplift these limitations. Koschenz \& Lehmann (2004) developed a thermally activated PCM ceiling panel for lightweight and retrofitted building applications [15]. Composite of gypsum and 25 weight percentage of microencapsulated PCM were used in the study to form a PCM composite panel stuffed in a metal case, which was equipped with water pipe for heat transmission. Another study which adopted the concept of thermally activated PCM was conducted by Lin et al.[18][19]. In their study, a shape-stabilized PCM is coupled with an under-floor electric heating to produce enormous thermal storage for peak load shifting. This system was able to reduce energy cost and $\mathrm{CO}_{2}$ emissions due to the fact that the PCM is charged over the night when the tariff and carbon intensity of the energy is lower than day time. Mazo et al. (2012) [20] developed a numerical model to simulate a PCM radiant floor heating system. The PCM floor heating system was coupled with a heat pump that operates during night time for the reduction of electricity cost. Their modelling results showed that heating demand was reduced by using PCM. In another study, Ansuini et al. (2011) [21]investigated a lightweight PCM floor radiant cooling system. The presence of PCM in the radiant cooling system managed to save approximately $25 \%$ of the energy consumption associated with cooling process for a room of $16 \mathrm{~m}^{2}$. It was also reported that in between seasons, the PCM was able to provide 2 to 3 days of thermal buffer in typical living conditions by buffering direct radiant gains from the sun.

From the above, radiant heating/cooling components are used to charge/discharge heat to/from PCM and initiate continuous thermal cycles in PCM. Most researchers use cheap electricity tariff to charge the PCM which will be used later during high tariff of electricity [18][19]. It can be noted that most of these studies use electric radiant system (high grade energy) embedded in building fabrics and PCM. To date, very little emphasis has been reported which integrate hydronic radiant system and PCM with potential low-grade energy. When active PCM is coupled with low-grade energy for heating/cooling, the thermal response of the system can be prolonged which reduces energy consumption for space heating and cooling. 
Furthermore, traditional active system using embedded regular-size piping suffers from the shortcomings such as huge size of piping and large space required for installation. TABS for instance, requires large surface areas for heat transfer to take place to provide enough thermal buffering for peak load shifting. Reducing the piping size as well as limiting the building structure for heat transfer interactions significantly reduce the effectiveness of TABS system as thermal inertia carried by the system is apparently lessened. This is where the combination of Capillary Tubes (CT) and PCM could offer a practical alternative to fill the gaps. CT could serve as a good replacement for the massive piping systems due to its small size, maximized contact surface and convenience for installation. PCM on the other hand, will provide sufficient thermal mass as a replacement of massive and bulky building structures.

Pipe material for CT varies from copper, steel and polyethylene [9]. The thermal conductivity of the pipe should be high enough to allow heat transfer between the water and the mass of the structure. It must also be durable, long lasting and corrosion free. Thus, the choice of pipe material is crucial as it affects the performance of the active system. The most frequently used pipe material in the study of hydronic radiant system is high-density polyethylene or polybutylene as it is flexible and can easily be assembled by heat treatment[22][23]. This makes it the primary choice of pipe material chosen for this study. Successful implementation of CT in active building has been reported where the thickness of concrete layer where the CT are to be installed can be as thin as $30 \mathrm{~mm}$ [24]. This is particularly attractive for retrofitting existing buildings and implementation on new buildings.

The present study aims to evaluate the thermal characteristics of a novel prototype of an active capillary tube embedded in PCM wall/ceiling panels. This is achieved by combining the passive PCM system with the hydronic capillary-tube radiant system. To our knowledge, this is the first study involving the combination of CT and PCM for active building heating and cooling purpose. In order to carry out the parametric studies, a theoretical model is developed to evaluate the thermal performance of the CT-PCM system and assess its long-term thermal performance. The model is evaluated against a set of experiments.

\section{Methods}

\subsection{Experimental design of CT-PCM system}

To understand the thermal characteristics of the CT-PCM system, an experimental design is shown in Fig.(1). The system comprises of 3 primary units which are the CT-PCM panel, temperaturecontrolled chamber and water bath system. The CT-PCM panel is a sandwich of PCM powder and 
capillary tube that is embedded at the centre of the PCM (Fig.(4)). The PCM used in this experiment was A23 Plus-ice micro-encapsulated PCM (paraffin) and its thermal properties are listed in Table 1. The CT-PCM panel is placed on the top of a temperature controlled chamber as shown in Fig.(2). The chamber is designed to regulate heating/cooling inside the chamber to provide variation of imposed temperature which will act as boundary conditions for the CT-PCM panel. A water bath with controllable water temperature is used to provide heating and cooling for the system via the capillary tubes (hydronic radiant system).

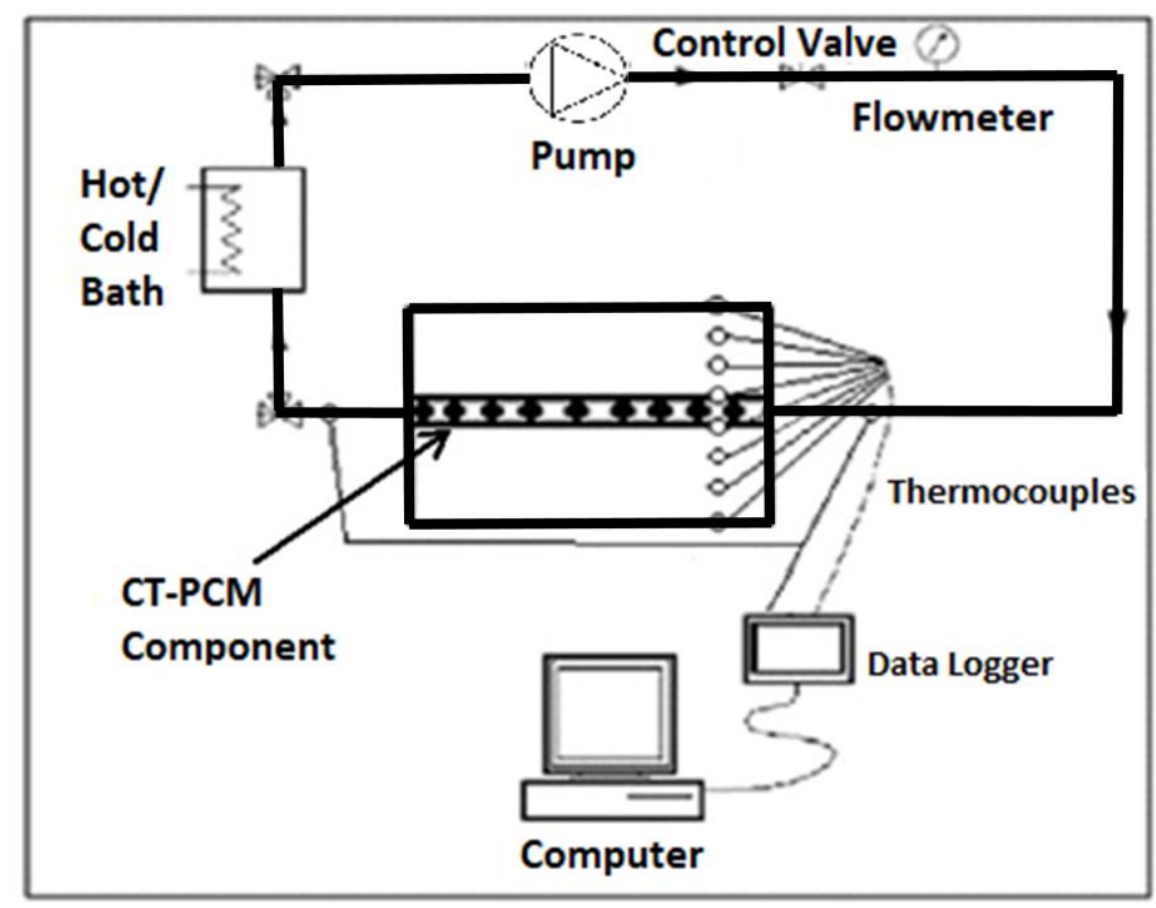

Fig 1. Schematic diagram for experiment

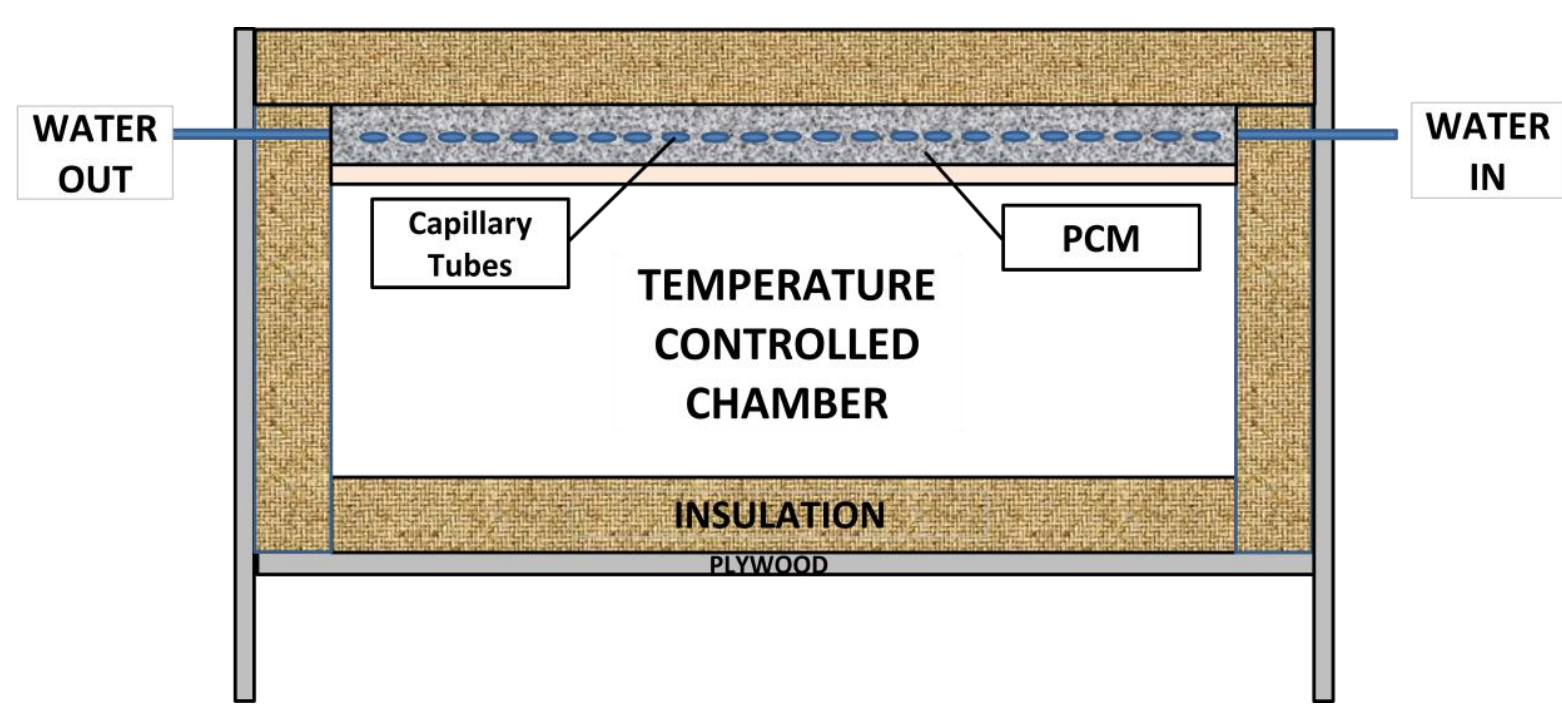

Fig 2. Schematic design of temperature-controlled chamber 


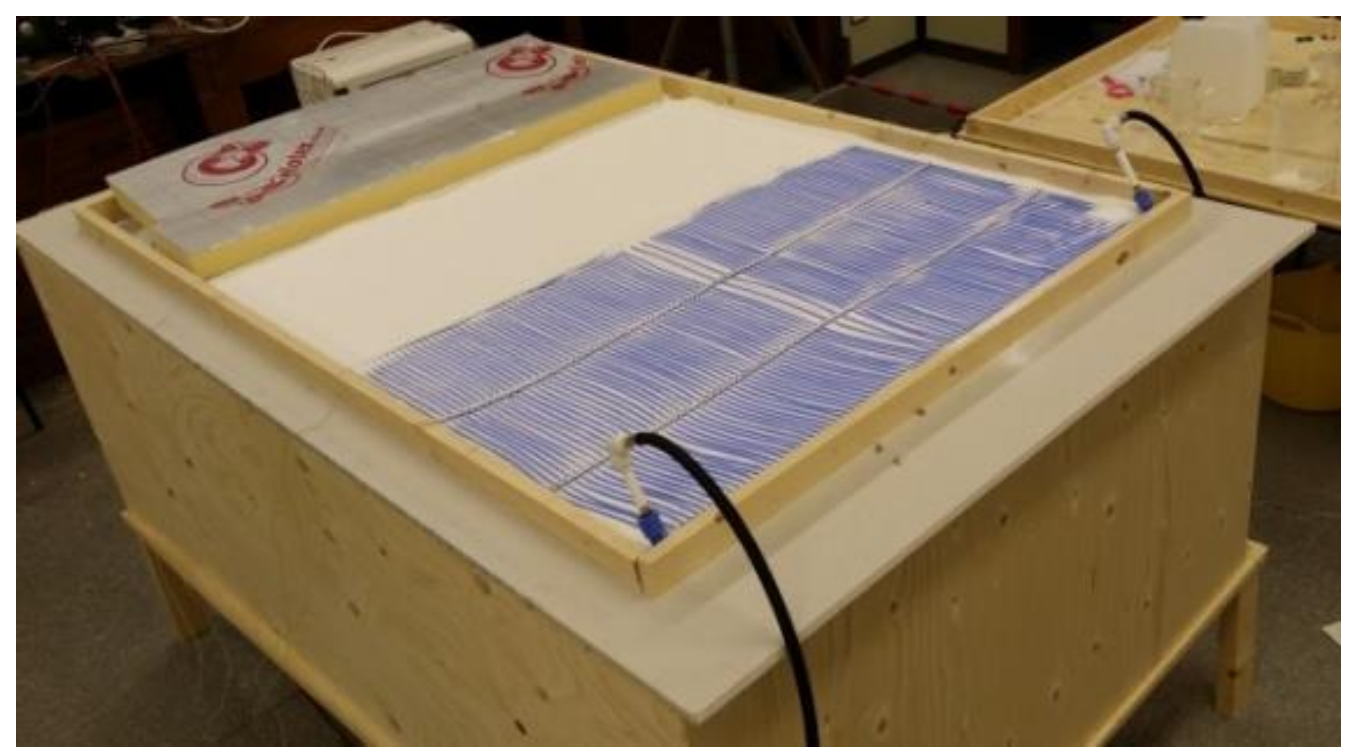

Fig 3. Real design of temperature-controlled chamber

Table 1. Thermal properties of PCM and plasterboard

\begin{tabular}{|l|c|c|c|c|c|c|}
\hline Material & $\begin{array}{c}\text { Density } \\
\rho, \\
\left(\mathrm{kg} / \mathrm{m}^{3}\right)\end{array}$ & $\begin{array}{c}\text { Thermal } \\
\text { conductivity } \\
\mathrm{k},\left(\mathrm{W} / \mathrm{m} .{ }^{\circ} \mathrm{C}\right)\end{array}$ & $\begin{array}{c}\text { Thickness } \\
(\mathrm{mm})\end{array}$ & $\begin{array}{c}\text { Heat } \\
\text { capacity } \\
\mathrm{c}_{\mathrm{p}}, \\
\left(\mathrm{J} / \mathrm{kg} .{ }^{\circ} \mathrm{C}\right)\end{array}$ & $\begin{array}{c}\text { Latent } \\
\text { heat } \mathrm{H}, \\
(\mathrm{kJ} / \mathrm{kg})\end{array}$ & $\begin{array}{c}\text { Melting } \\
\text { Temperature } \\
\left({ }^{\circ} \mathrm{C}\right)\end{array}$ \\
\hline $\begin{array}{l}\text { A23 Plus Ice } \\
\text { micro- } \\
\text { encapsulated } \\
\text { PCM }\end{array}$ & 785 & 0.18 & 11 & $\begin{array}{c}2220 \\
\text { average } \\
\text { for solid } \\
\text { and } \\
\text { liquid })\end{array}$ & 210 & 21 \\
\hline $\begin{array}{l}\text { Gypsum } \\
\text { board }\end{array}$ & 800 & 0.17 & 22 & 1090 & - & - \\
\hline
\end{tabular}

The exposed capillary tubes are embedded in PCM powder which is then insulated on the top of the panel. Capillary tubes used in the system is plastic capillary tube which is $140 \mathrm{~m}$ long with inner diameter of $3.4 \mathrm{~mm}$ and $0.55 \mathrm{~mm}$ thickness (Outer diameter $=4.5 \mathrm{~mm}$ ). The tube allows hot and cold water flow to exchange heat with the PCM. During PCM charging, heat from hot water is transferred to PCM where melting process is predicted when heat is supplied above the melting temperature of the PCM. During PCM discharging, heat from PCM is transferred back to the Heat Transfer Fluid (HTF). The thermal properties of the PCM and plasterboard used are displayed in table 1.The chamber $(1.2 \mathrm{~m} \times 1.3 \mathrm{~m} \times 2.0 \mathrm{~m})$ is constructed using plywood where the CT-PCM is placed on the top of the chamber (ceiling). The chamber is fully insulated to avoid heat loss or thermal interference 
from outside. Heating in this setup is supplied through an adjustable $2 \mathrm{~kW}$ convective heater and cooling is supplied from ice cubes. A fan is used to ensure a well mixing of air inside the chamber. An actual temperature chamber fabricated for the experiment is shown in Fig.(3).

Temperature across the depth of the CT-PCM panel is measured using Type K thermocouples with an accuracy of $\pm 0.1^{\circ} \mathrm{C}$. The data logging system of Picolog is used to monitor and collect the temperature distribution per minute across the thickness of the CT-PCM panel which is shown in Fig.(4). Here, thermocouples are placed at node marked as T0, T1, T2, T3 and T4 where the temperature distribution for all these nodes will be recorded. As discussed in section 2.2.4, 6 distinct points on the CT-PCM panel are chosen for validation as shown in Fig.(7).

Throughout the experiment, the PCM thickness is kept the same, but the flow rate and supply temperature from the hydronic system varies, allowing the dynamic response of the CT-PCM system. Five sets of experimental scenarios are conducted, see Table 2.

Table 2. Experimental scenarios

\begin{tabular}{|c|c|c|c|}
\hline Scenarios & $\begin{array}{c}\text { PCM Thickness, } \\
(\mathbf{m m})\end{array}$ & $\begin{array}{c}\text { Flow rate, } \\
(\mathbf{m l} / \mathbf{m i n})\end{array}$ & $\begin{array}{c}\text { Water supply } \\
\text { temperature, }\left({ }^{\mathbf{C}} \mathbf{C}\right)\end{array}$ \\
\hline Test $\mathbf{1}$ & 11 & 300 & 5 \\
\hline Test $\mathbf{2}$ & 11 & 300 & 10 \\
\hline Test 3 & 11 & 500 & 10 \\
\hline Test $\mathbf{4}$ & 11 & 800 & 10 \\
\hline Test $\mathbf{5}$ & 11 & 1000 & 15 \\
\hline
\end{tabular}

\subsection{Development of a numerical model for CT-PCM}

The CT-PCM is a complex thermal system which involves different heat transfer processes such as heat transfer during phase change process, heat conduction from the internal layers and heat transfer from the capillary tubes. For a common radiant system embedded in a slab, Laouadi (2004) [2]suggested a fundamental heat diffusion equation to estimate the thermal performance of the system as in Eq.1. This model is based on linear properties of building materials. This expression is however incompatible with PCM as it inherits a non-linearity [25]. Therefore, in this study, transient enthalpy method has been adopted to evaluate the thermal behaviour of PCM [26]-[28] in the system. This method is employed to estimate the heat transfer for the CT-PCM system by using temperature measurement at boundary nodes. Fig. 4 shows the geometry for the system that is used in the modelling. The ceiling or wall structure is formed of three-layer plane walls where the PCM is 
sandwiched between the plaster and the insulation board. Capillary tubes are embedded in the PCM. Varying temperature is imposed at $\mathrm{x}=0$ as boundary condition and the PCM is insulated on the top.

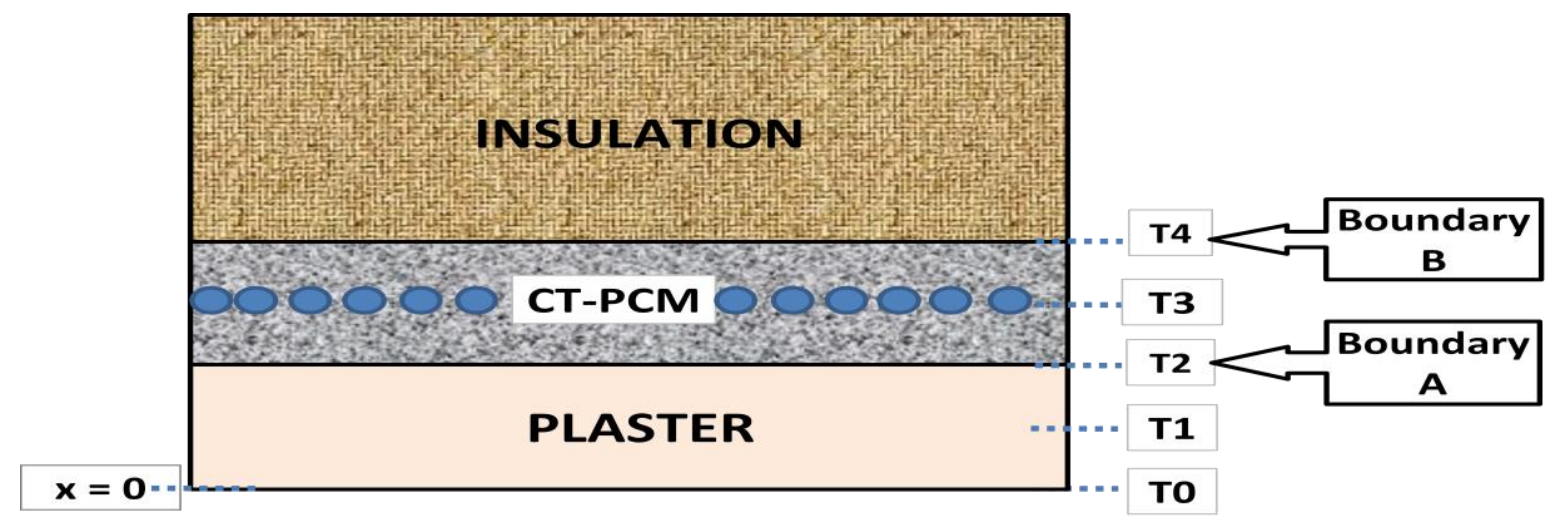

Fig 4.Geometry for numerical simulation.

\subsubsection{Governing equations}

Governing equations of CT-PCM system write according to [2],

$\rho \frac{\partial \mathrm{H}}{\partial \mathrm{t}}=\frac{\partial}{\partial \mathrm{x}}\left(\mathrm{k} \frac{\partial \mathrm{T}}{\partial \mathrm{x}}\right)-\rho \mathrm{L} \frac{\partial \mathrm{f}}{\partial \mathrm{t}}-\frac{\partial q_{w}}{\partial \mathrm{x}}$

$\dot{q}_{w}=\frac{\dot{m}_{w} * c_{p, w}\left(\mathrm{~T}_{\mathrm{w}, \mathrm{out}}-\mathrm{T}_{\mathrm{w}, \text { in }}\right)}{A}$.

$\rho \frac{\partial \mathrm{H}}{\partial \mathrm{t}}=\mathrm{k}\left(\frac{\partial^{2} \mathrm{~T}}{\partial \mathrm{x}^{2}}\right)-\rho \mathrm{L} \frac{\partial \mathrm{f}}{\partial \mathrm{t}}-\frac{\partial q_{\mathrm{w}}}{\partial \mathrm{x}}$

The following assumptions are taken when modelling radiant tubes embedded in PCM [2];

- The temperature gradients between tubes are neglected and considered as uniform when the ratio of the tube spacing to circuit length is very small.

- The radiant system edges are adiabatic (well insulated).

- Temperature gradients within the tubing material are negligible when the tubing thickness is very small compared to the interior diameter.

$q_{w}$ is heat transfer per unit area as given in equation 2, which is calculated from mass flow rate and specific heat of water as well as inlet and outlet water temperature of the capillary mat. The consideration of using $q_{w}$ in the model will be discussed in the following subsection. Heat transfer in the plane wall is assumed to be unidirectional and when thermal conductivity is constant, $\mathrm{Eq}(1)$ can be therefore reduced to $\mathrm{Eq}(3)$. 


\subsubsection{Numerical computation and stability}

Finite difference method is employed to solve the governing equations. From Fig.(5), the plane wall is discretised with a uniform spatial step known as nodes and uniform time step [29]. Each node is governed by a control volume where energy balance equations are assigned at each node and time step.Varying temperature is imposed at node $0(\mathrm{x}=0)$ and radiant heat is supplied at $T_{3}$. For stability, the time step and the spatial step must be chosen such that,

$\max \left|\frac{k \Delta t}{\rho c \Delta x^{2}}\right| \leq \frac{1}{2}$

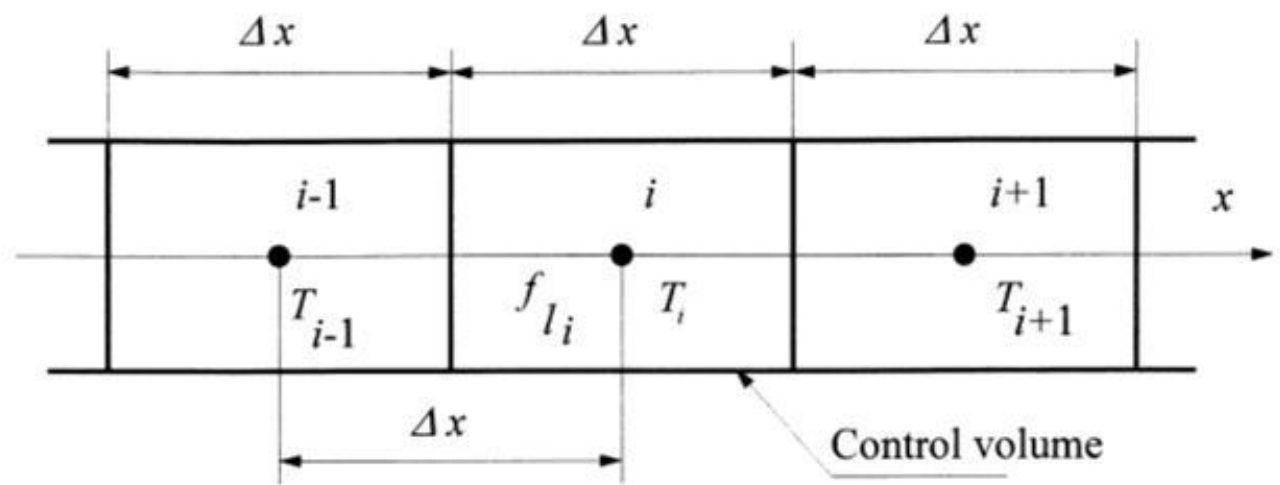

Fig 5.Discretisation for one dimensional phase change problem [29].

For one dimensional phase change within a plane wall, the governing enthalpy equation of CT-PCM system is given as

$\frac{\partial H}{\partial t}=\frac{\partial}{\partial x}\left(\frac{k}{\rho} \frac{\partial T}{\partial x}\right)-L \frac{\partial f}{\partial t}-\frac{\dot{q}_{w}^{i}}{\rho \Delta x}$

Explicit discretisation of inner node $i$ will give,

$\frac{\partial H_{i}}{\partial t}=\frac{k}{\rho \Delta x^{2}}\left(T_{i-1}-2 T_{i}+T_{i+1}\right)-L \frac{\partial f_{i}}{\partial t}-\frac{\dot{q}_{w}^{i}}{\rho \Delta x}$

First term in equation (6) represents the sensible enthalpy whereas the third term represents liquid fraction $\left(f_{i}\right)$ of PCM when phase change occurs, and the latent heat is represented by $(\mathrm{L})$. The last term is heat per unit area from radiant system which is embedded in PCM. In the modelling, the last term is only applicable at $T_{3}$ where the capillary is embedded and heat, $q_{w}$ is extracted or removed. Equation 6 is left as it is for numerical computation. When no phase change occurs, the third term equals to zero where the change of sensible energy is computed from the knowledge of previous and after temperatures of current node in the control volume given by equation 7 .

$\frac{\partial H_{i}}{\partial t}=\frac{k}{\rho \Delta x^{2}}\left(T_{i-1}-2 T_{i}+T_{i+1}\right)-\frac{\dot{q}_{w}^{i}}{\rho \Delta x}$

It should also be noted that the first term in equation 7 can be reduced to an ordinary heat diffusion equation; 
$\frac{\partial H_{i}}{\partial t}=c \frac{\partial T_{i}}{\partial t}$

where $\mathrm{c}$ is the specific heat of either solid or liquid depending on the state of the control volume. Equation 7 can be re-written as;

$\frac{\partial T_{i}}{\partial t}=\frac{k}{\rho c \Delta x^{2}}\left(T_{i-1}-2 T_{i}+T_{i+1}\right)-\frac{\dot{q}_{w}^{i}}{\rho c \Delta x}$

Discretising the first term of equation 9 using backward difference, temperature of each node of single material can be obtained as below;

$T_{i}^{j+1}=T_{i}^{j}+\frac{k \Delta t}{\rho c \Delta x^{2}}\left(T_{i-1}^{j}-2 T_{i}^{j}+T_{i+1}^{j}\right)-\frac{\dot{q}_{w}^{i} \Delta t}{\rho c \Delta x}$

When phase change occurs (melting or freezing), the first term of equation 6 equals zero. This is due to the fact that the change of sensible energy is less significant compared to the latent thermal storage of PCM in a phase changing mode. Rearranging eq. (6) will result in the following;

$L \frac{\partial f_{i}}{\partial t}=\frac{k}{\rho \Delta x^{2}}\left(T_{i-1}-2 T_{i}+T_{i+1}\right)-\frac{\dot{q}_{w}^{i}}{\rho \Delta x}$

Discretising the first term of equation 11 using backward difference, liquid fraction of each node of single material can be obtained as below;

$f_{i}^{j+1}=f_{i}^{j}+\frac{k \Delta t}{\rho L \Delta x^{2}}\left(T_{i-1}^{j}-2 T_{i}^{j}+T_{i+1}^{j}\right)-\frac{\dot{q}_{w}^{i} \Delta t}{\rho L \Delta x}$

For solid, $f=0$ and for liquid, $f=1$. Any fraction which is less than 0 or greater than 1 is corrected to 0 and 1 respectively.

Equation 10 and 12 are only applicable for inner nodes of the same material. Outer nodes are subjected to boundary conditions at $\mathrm{x}=0$ and $\mathrm{x}=\mathrm{L}$. Interface node of different materials would have to consider the difference of thermo-physical properties for both materials while formulating the equations.

In Fig.(4), there are 5 nodes of equally spaced $\Delta x=5 \mathrm{~mm}$, where node $0(\mathrm{x}=0)$ and node 4 $(\mathrm{x}=\mathrm{L})$ are the boundary nodes. Node 2 is an interface node between a gypsum board and PCM whereas node 1 and 3 are inner nodes of the same material. It should be noted that node 2, 3 and 4 are PCM nodes where phase change process is anticipated when melting or freezing temperature is met.

The initial condition is,

$T(x, 0)=T_{0}$ 
Assumptions for numerical computation:

i. One-dimensional heat transfer through the wall

ii. Thermo-physical properties of the layers are constant except for the specific heat of PCM during melting or freezing process

iii. Natural convection of PCM during melting process and the super-cooling effect during freezing process can be ignored.

iv. $\quad$ PCM is assumed to behave ideally where property degradation is not considered.

v. PCM is homogenous and isotropic.

vi. Steady flow and uniform heat distribution through the capillary tubes across the wall layers.

\subsubsection{Switching between one-phase or dual-phase computation}

The computation mentioned above is strictly depending on the state of PCM during the iteration process. Iteration normally starts when the PCM is in one phase (completely solid or liquid). During this period, Eqs. (9)-(10) are applicable. Temperature distribution during each time step is calculated using Eq. (10) above. This will continue until the nodal temperature within the PCM reaches the melting/freezing point. After this point, it is assumed that PCM is in dual-phase condition where the temperature is kept constant at its melting/freezing point. The following equation applies when PCM is in dual-phase.

$T_{i}^{j+1}=T_{i}^{j}=T_{m}$

During the dual-phase period, Eqs. (11)-(12) are applicable. The phase change process is assumed to take place isothermally where only liquid fraction is determined explicitly for every time steps using Eq. (12). The correlation for liquid fraction is given in equation below;

$f_{i}=\left\{\begin{array}{c}0 \text { if } T<T_{m}(\text { Solid }) \\ 1 \text { if } T>T_{m} \text { (Liquid) } \\ \text { between 0and } 1 \text { during phase change }\end{array}\right.$

It should be noted that the value for liquid fraction falls between 0 and 1 during phase change. It is 0 when PCM is solid and it is 1 when it is completely liquid. Values beyond this point will be corrected to 0 and 1 respectively. For melting process, iteration for liquid fraction starts at 0 the moment PCM nodal temperature reaches its melting temperature at $T_{m}$. Eq. (12) is used to calculate the liquid fraction explicitly for every time steps until it reaches 1 . This means that the material has fully melted and the temperature is allowed to rise again. For the temperature iteration after the PCM has fully melted, the computation shifts back to Eq. (10). It is important to remember that once the liquid 
fraction has been determined, the temperature field during the phase change process (initially assumed isothermal)can be corrected using the following formula;

$T_{i}=T_{S}+f_{i}\left(T_{L}-T_{S}\right)$

where

$\mathrm{T}_{\mathrm{i}}$ the temperature for current node $\left({ }^{\circ} \mathrm{C}\right)$,

$\mathrm{T}_{\mathrm{L}}$ the upper limit melting temperature $\left({ }^{\circ} \mathrm{C}\right)$,

$\mathrm{T}_{\mathrm{s}}$ the lower limit melting temperature $\left({ }^{\circ} \mathrm{C}\right)$,

$f_{\mathrm{i}}$ the liquid fraction for current node.

Similarly, for freezing process, the PCM starts off as liquid where its nodal temperature field can be determined using Eq. (10). The moment the temperature of the PCM reaches the freezing point, the temperature is assumed to stay constant during the freezing process. Unlike melting process, the iteration for liquid fraction during freezing process starts at 1 and goes all the way down to 0 . Eq. (12) is used to calculate the liquid fraction. After the fraction reaches 0 , the temperature is allowed to change again by shifting it back to Eq. (10). The computation process of the numerical modelling is represented in Fig.(6). Last but not least, the enthalpy field (sensible and latent) can be calculated using the Eq. (17) once the temperature field and liquid fraction have been finalised.

$\mathrm{h}_{\mathrm{i}}^{\mathrm{j}+1}=\left(\mathrm{C}_{\mathrm{avg}} \times \mathrm{T}_{\mathrm{i}}^{\mathrm{j}+1}\right)+\left(\mathrm{f}_{\mathrm{i}}^{\mathrm{j}+1} \times \mathrm{L}\right)$

\subsubsection{Special consideration of $q_{w}$}

From Eq. 1, $\boldsymbol{q}_{w}$ represents the amount of heat from the capillary tubes. It is calculated with the knowledge of mass flow rate, specific heat of fluid and temperature difference between inlet and outlet of a heat exchanger as shown in Eq. 2. This equation is valid under the condition of steady state and incompressible fluid flow. This conventional equation is mostly used by researchers due to its simplicity and applicability in complex problems [30]. As the capillary mat is completely buried in the PCM powder, it can be assumed that heat lost/gained from the capillary mat is completely transferred to/extracted from the PCM. In order to observe the effectiveness of using $\boldsymbol{q}_{w}$ in the modelling, 6 points along the CT-PCM panel are identified in Fig.(7) and the model for each of these points will be verified using experimental data. As far as validation process goes, comparison of temperature profiles at PCM boundary nodes are performed between the model and the experiment data. These two points are measurable from the experiment which will be the base on validation between the model and the experiment. 


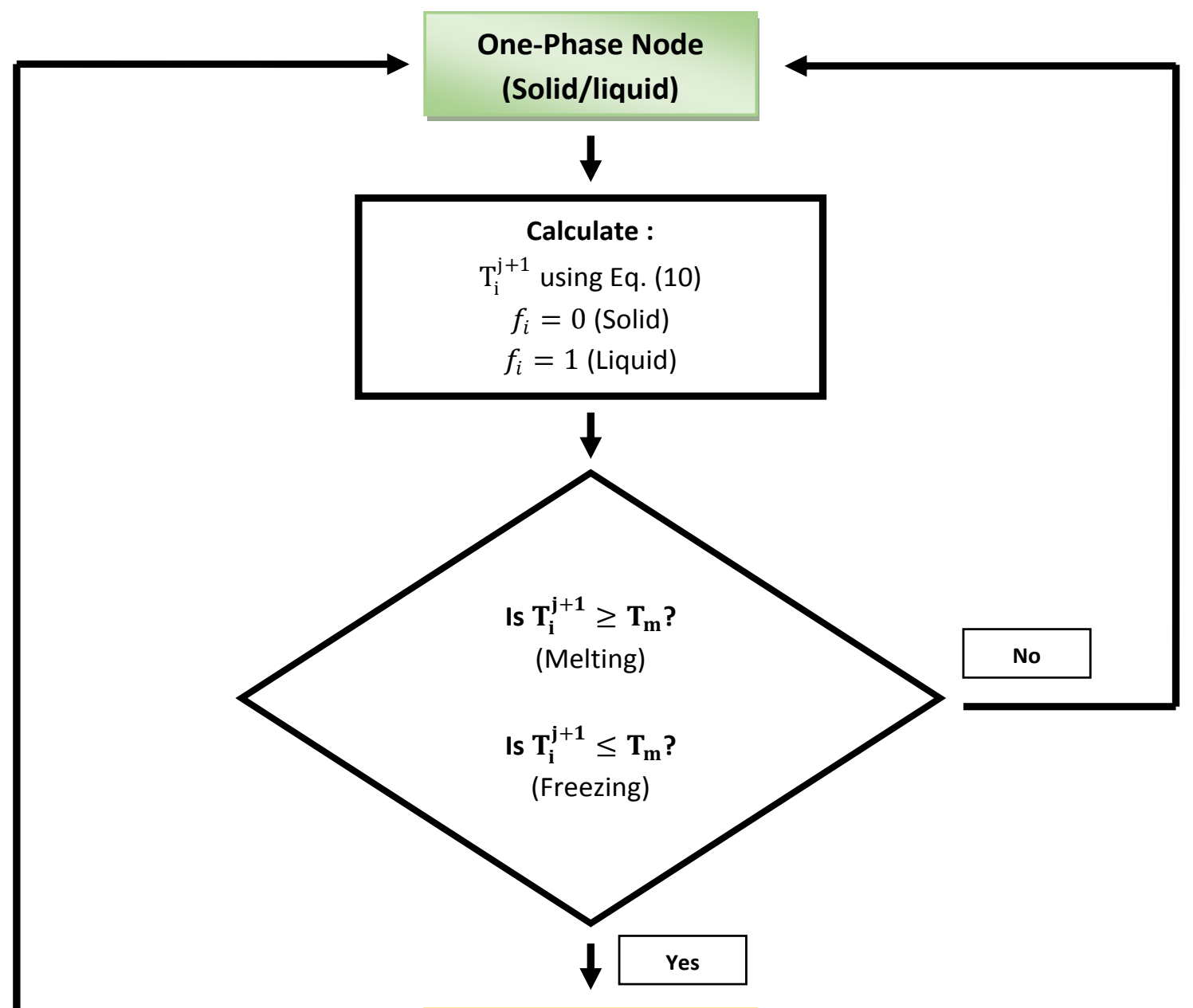

Dual-Phase Node

(Solid + liquid)

$\downarrow$

Calculate :

$f_{i}$ using Eq. (12)

$\mathrm{T}_{\mathrm{i}}^{\mathrm{j}+1}=\mathrm{T}_{\mathrm{i}}^{\mathrm{j}}=T_{m}$

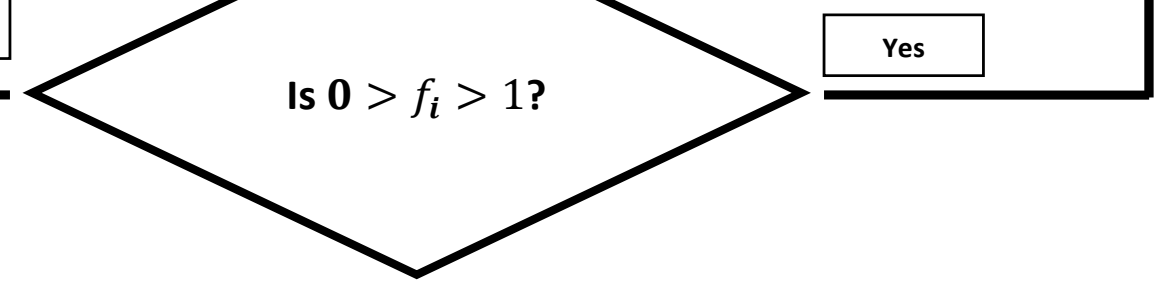

Fig 6. Computation process for single and dual-phase PCM. 
From earlier definition, $\boldsymbol{q}_{\boldsymbol{w}}$ is assumed to be uniform throughout the entire panel which means the validation of the identified 6 points will be based on the same $\boldsymbol{q}_{w}$. If the model is able to be validated reasonably for all the identified points, then previous assumptions are right that uniform $\boldsymbol{q}_{w}$ can be used in the model to represent the heating/cooling from the capillary mat. Nevertheless, some constraints may affect the accuracy of the data from the experiment. As PCM powder is used in the experiment, uneven PCM thickness is one big challenge that needs to be addressed. PCM thickness determines the latent heat storage for the system. Thus, uneven thickness could lead to big errors in modelling. Another problem that could emerge is the capillary tube which may not be properly buried at the centre of the PCM panel. Before the experiment begins, the tube must be guaranteed to be at the centre so that heat is evenly distributed through both surfaces on the CT-PCM panel to ensure accurate modelling. The 6-point validation results and the validity of $\boldsymbol{q}_{w}$ will be discussed in results and discussion.

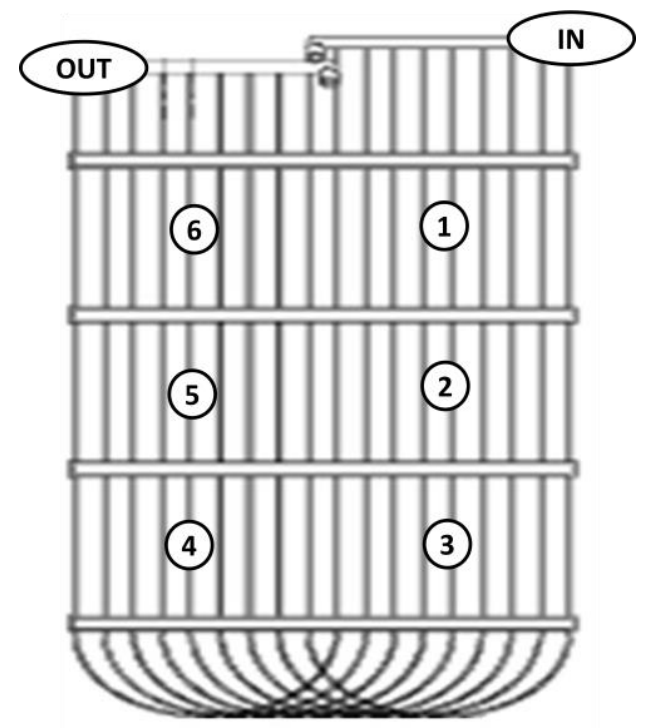

Fig 7. Measurement points on CT-PCM panel

\section{Results and discussions}

In this section, verification of the model with experiment data is conducted under two different scenarios. The first scenario deals with the validation of PCM-only system and the second scenario is the validation of CT-PCM. The main reason to conduct the validation of PCM-only system is to assess the reliability of PCM technical specifications given by manufacturer. It is often found in literature that the manufacturers give misleading information on the technical specifications of PCM. Before continuing the experiment with embedded tubes in the PCM system, it is important to reassure that the technical specifications given for the purchased PCM is acceptable and reliable as the modelling is dependent on the accuracy of the thermal properties given. 


\subsection{Comparison of modelling and experimental results for PCM-only component}

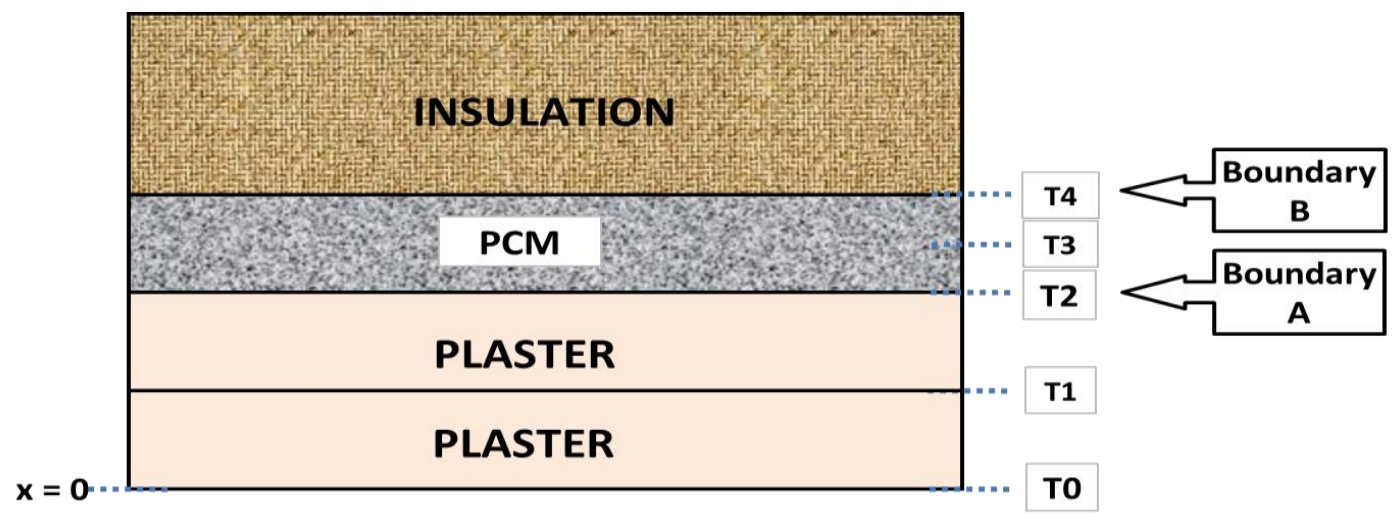

Fig 8. Schematic diagram for numerical modelling for PCM-only component

For PCM-only experiment, the case is filled with microencapsulated powder PCM (without tubes) and placed on the top of the temperature-controlled chamber. In this experiment, heating process is initiated on the frozen PCM which is chilled beforehand. It is important to note that in order to evaluate the thermal performance of PCM, the PCM needs to undergo a full thermal cycle of phase change process. In this case, the powder PCM is chilled in freezer around $10^{\circ} \mathrm{C}$ below its melting temperature $\left(21^{\circ} \mathrm{C}\right)$. Initial temperature of the PCM is checked before filling the PCM in its case to ensure that the PCM is fully frozen. Heating from the chamber is initiated and temperature evolutions at specified thermocouple locations are recorded using data logger as shown in Fig.8. The temperature at PCM boundary nodes are taken as comparison between the experiment and the model. These points reflect the change of sensible and latent thermal storage for the PCM during phase change process and have been taken as reference points in other PCM validation studies [31].The modelling for this case is performed using numerical model described in section 2 above without integrating the heat from the tubes.

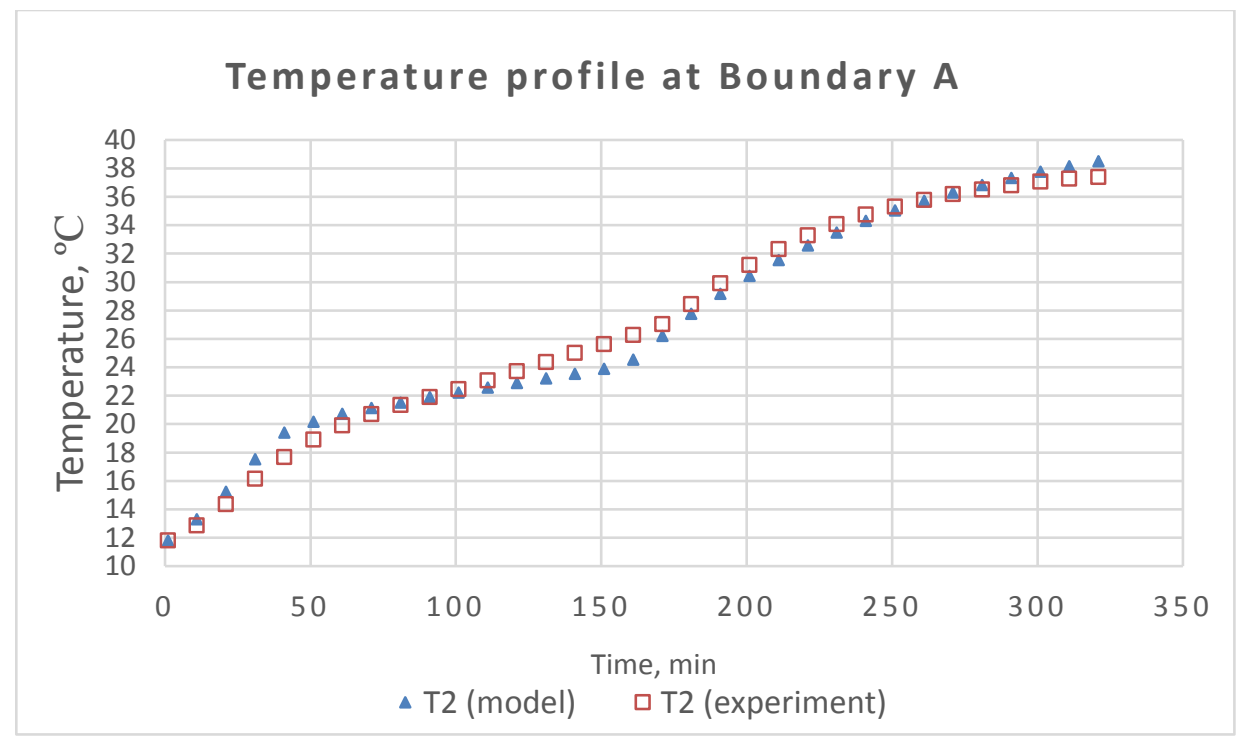


Fig 9.Comparision of the experimental results and the outcomes of numerical model at PCM boundary A.

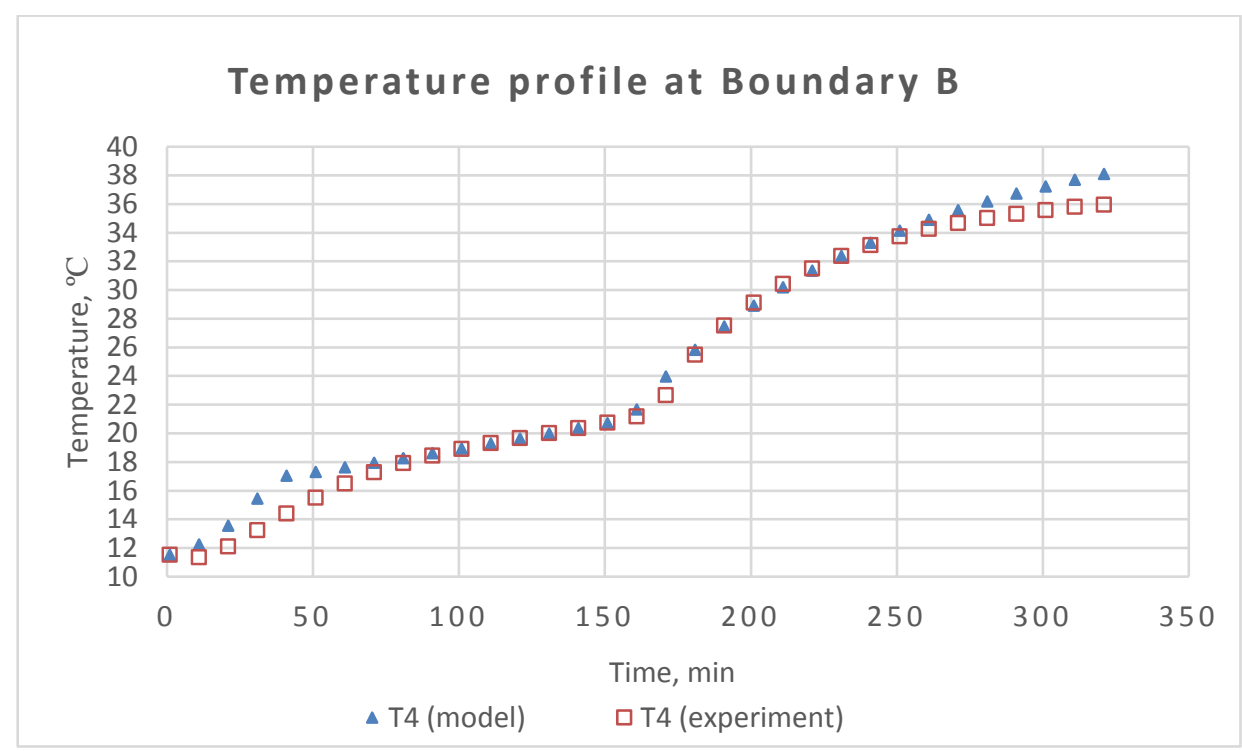

Fig 10. Comparison of the experimental results and the outcomes of numerical model at PCM boundary B.

By using the thermal properties provided in Table 1 and with the assembly as shown in Fig.8, the validation results between the experiment data and the model are displayed in Fig.9 and Fig.10above. The models in both respective points are in good agreement with the experiment data. The temperature starts off at about $10^{\circ} \mathrm{C}$ and continues to rise steeply until it gets around $18^{\circ} \mathrm{C}$. In this period, the PCM is frozen (solid state) and the temperature change is only due to the sensible heat storage of the PCM. A more gradual temperature increase is noticeable after this point until it gets to about $22^{\circ} \mathrm{C}$ before a sharp temperature increase is observed. This is due to the fact that the PCM is melting between $18^{\circ} \mathrm{C}$ to $22^{\circ} \mathrm{C}$ and the temperature continues to soar when melting is completed and the PCM is in liquid state. During melting, heat that is supplied to the PCM is used in the phase change process which makes the temperature to increase slowly. It takes longer for the temperature to increase during heating due to sensible and latent thermal storage of PCM. In liquid state, only sensible storage is present which makes temperature to increase sharply. Due to the successful verification of the model with provided technical specifications, the validation process is extended to the model of CT-PCM system which will be discussed in the next section.

\subsection{Comparison of modelling and experimental results for CT-PCM}

The system is set similarly as PCM-only system with the same chamber. The only difference between the two settings is that capillary tubes are embedded in the middle of the PCM for CT-PCM. For the validation, CT-PCM will undergo cooling process which is initiated by the tubes embedded in the PCM. As discussed above, the PCM needs to undergo a full thermal cycle between solid to liquid or 
liquid to solid to evaluate the thermal performance of the system. For this purpose, the PCM is heated up to $30^{\circ} \mathrm{C}$ to ensure that the PCM is in liquid state. Then, cooling is initiated through the tubes and the temperature changes in the system are measured by thermocouples. The temperature difference between the inlet and the outlet of the tubes delivers heat transfer to the adjacent medium (PCM) which is used in calculation of $\mathrm{q}_{\mathrm{w}}$. Five different conditions of experiment scenarios are performed in the study which are displayed in Table 2.For simplicity, only results from test 5 will be displayed and discussed whereas the rest of the modelling results and their validation are displayed in Appendix 1.

The modelling of CT-PCM system has been explained in section 3. Similarly, with PCM heating process, the PCM boundary nodes are taken as reference for verification between the measured data and the numerical model. The first important finding of the experiment is that the model has been successfully validated under different experimental conditions while the flow-rate of thermal fluid is equal to or above $800 \mathrm{ml} / \mathrm{min}$. However, at low flow-rate below $500 \mathrm{ml} / \mathrm{min}$, a correction factor needs to be applied to the cooling flux, $\mathrm{q}_{\mathrm{w}}$ in order to get a satisfactory validation of the model. Correction factor serves as an adjustment between the model and the experiment data. It represents the concentrated heat flux at the six measuring points along the CT as shown in Fig.13.

In earlier section, it is assumed that heat is uniformly distributed throughout the entire capillary mats. From the results, this assumption is satisfactory when fluid flow is maintained at high flow rate $(\geq 800$ $\mathrm{ml} / \mathrm{min}$ ) inside the capillary tubes. However, when fluid flow inside the tubes is maintained at low flow rate $(\leq 500 \mathrm{ml} / \mathrm{min})$, this assumption is observed to be untrue. This is because temperature gradient near to the entrance of the capillary tubes is higher and it diminishes as it flows along the capillary tubes. Under uniform heat distribution assumption, HTF is absorbing heat flux evenly throughout the entire panel between the $\mathrm{CT}$ and temperature chamber. At low flow rate, HTF allows more heat to be absorbed per unit time as it flows slowly through the tube corresponding to the temperature gradient between the CT and the temperature chamber. This creates a concentrated heat flux on the capillary mat that allows greater heat transfer at the inlet of the capillary tubes and it diminishes as it flows along the tubes to the outlet as shown in Fig.13.

Assumption on uniform $\mathrm{q}_{\mathrm{w}}$ can only work when modelling CT-PCM at high flow rate above 800 $\mathrm{ml} / \mathrm{min}$. To compensate this drawback, correction factor can be introduced to satisfy the assumption on uniform $\mathbf{q}_{\mathbf{w}}$ at low flow rate of CT-PCM. This allows standardisation on modelling assumption regardless of the volume flow rates of the system. Nevertheless, due to the uncertainty of the correction factor, a threshold limit on the flow rate above $800 \mathrm{ml} / \mathrm{min}$ should be set for future application of the numerical model.

\subsubsection{Correction factor for low flow rate cooling}


In order to determine the correction factor, a comparison is made between the experimental data and the model without using correction factor while assuming uniform $\mathrm{q}_{\mathrm{w}}$ for the modelling. Fig.11and Fig.12 show the model and experimental data at point 2(Fig 8) for test 2(Table 2). It can be seen that the results of the numerical model is not in line with the experiment data. The function of a correction factor is that it enables uniform $\mathrm{q}_{\mathrm{w}}$ to be applied throughout the entire capillary mats regardless of the volume flow rate of the CT-PCM. Earlier on, we discuss that heat flux is greater at the inlet for capillary system with low flow rate as most heat is transferred at the entry part of the tubes. Looking at the expression for uniform heat flux, $\dot{q}_{w}=\dot{m} c_{p} \Delta T$, it is understood that for incompressible flow and constant specific heat, the change of heat flux is depending solely on the change of temperature gradient for the system. Thus, the correction factor is applied to the temperature gradient from the general expression above during the model computation. For this, an initial guessed correction factor is applied to 50 percent of the computed data. Value adjustment will be carried out until gaps shown in Fig.11 and Fig.12 can be reduced satisfactorily between the model and the experiment data. The guessed value serves as an estimate for the first half set of the data and it is used to predict the remaining half of the computed data. Once the set value is finalised, the final half of the data will be computed using this value and the computation process will progress as systematically planned as shown in Fig.5. The process is iterated. When a good match between the model and the experiment data is obtained, the correction factor for that measuring point is recorded for future reference. Subsequently, the method is applied for all of the measuring locations on the capillary mat and the correction factors obtained are displayed in Fig.13 below.

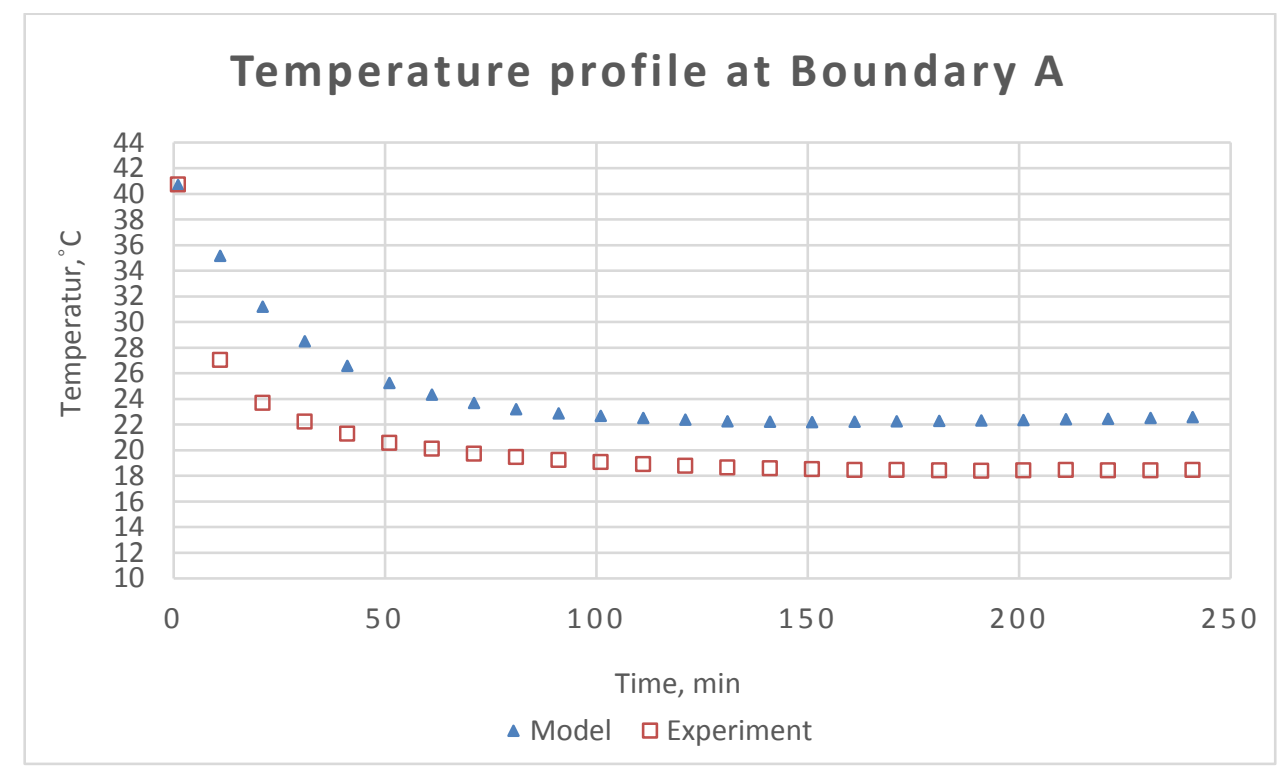

Fig 11. Verification without correction factor (Boundary A) 


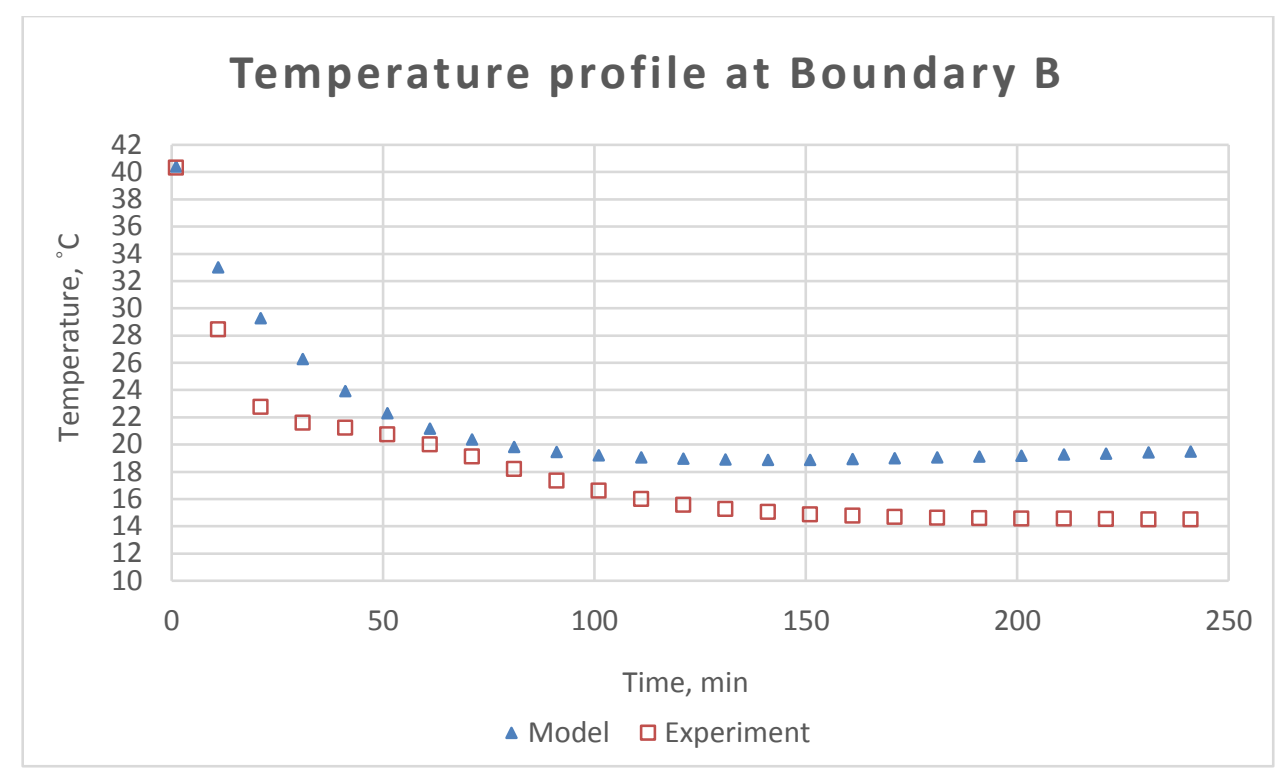

Fig 12. Verification without correction factor (Boundary B).

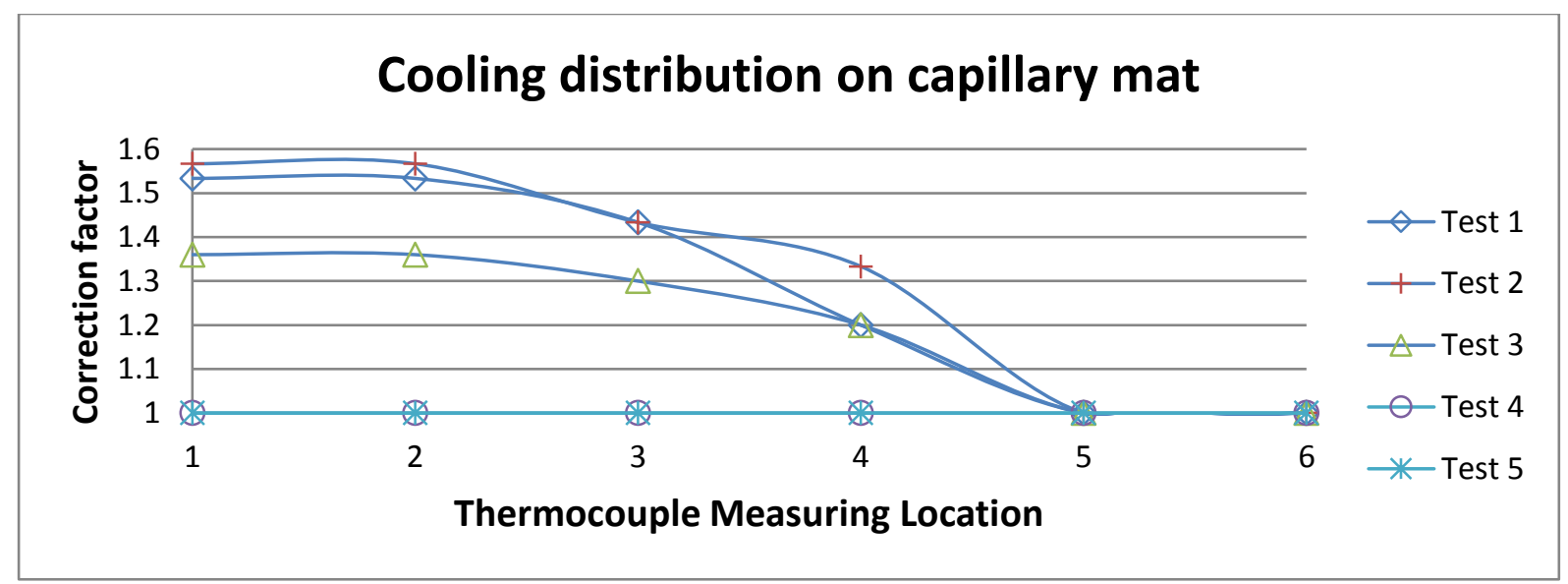

Fig13. Application of correction factor on $\mathrm{q}_{\mathrm{w}}$.

From Fig.13, it can be seen that the correction factor is strongly influenced by the flow-rate of the capillary tube. At high flow-rate above $800 \mathrm{ml} / \mathrm{min}$ (test $4 \& 5$ ), no correction factor is needed where uniform $\mathrm{q}_{\mathrm{w}}$ can be used satisfactorily to represent cooling power from CT in modelling. On the contrary, at low flow rate below $500 \mathrm{ml} / \mathrm{min}$ (test 1,2 \& 3), correction factor needs to be introduced for accurate modelling of cooling power from the CT. If no correction factor is applied, an error of up to $56 \%$ could be introduced in the model. It is also apparent in Fig.13 that the correction factor diminishes as it goes along the measuring point from 1 to 6 . For this, it can be understood that the temperature difference in a CT is higher closer to the inlet and it will gradually decrease as it moves along the tubes to the outlet. Therefore, assuming that the heat is uniformly distributed at a low flow rate in CT will generate significant error in model simulation unless correction factor is applied. There is a threshold flow rate where uniform $\mathrm{q}_{\mathrm{w}}$ can be used in the model for CT-PCM. In this study, it is above $800 \mathrm{ml} / \mathrm{min}$. It is also important to note that the correction factor reduces with increasing 
volume flow rate as shown in Fig.13. This shows that less heat transfer is experienced as temperature gradient is reduced especially at the inlet of CT due to increased velocity of the fluid.

\subsubsection{Comparison for CT-PCM}

The results (test 5) for the CT-PCM validation are presented below. However, for simplicity, only data from measuring point 2 and 5 will be displayed as they are located in the middle of the CT.

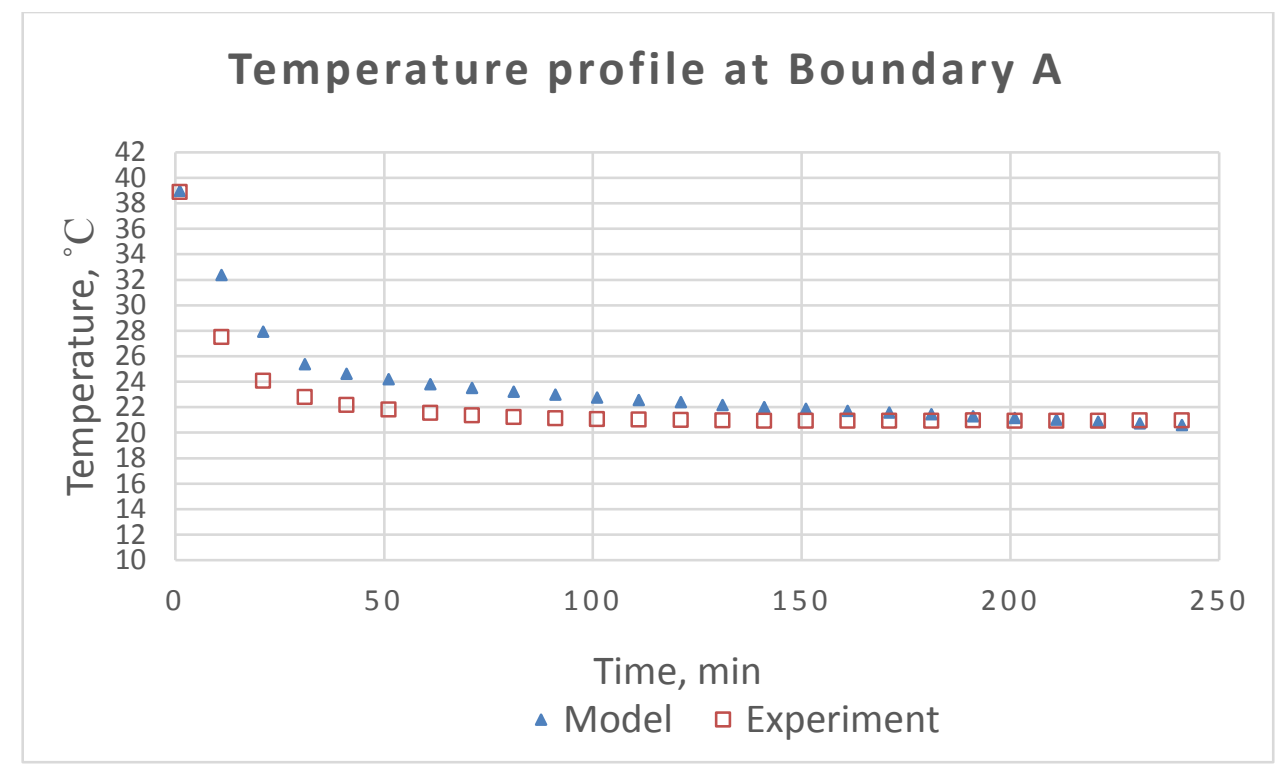

Fig 14. Validation results for Measuring Point 2 (Boundary A)

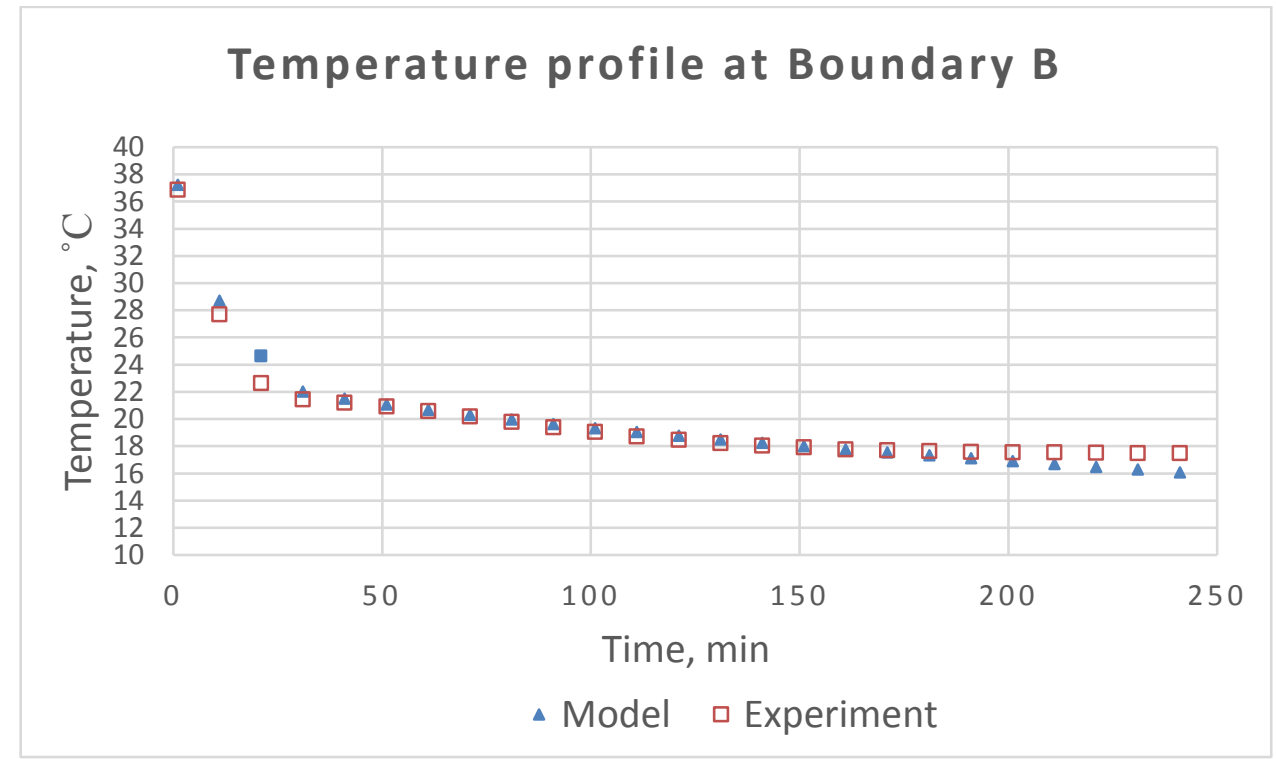

Fig 15. Validation results for Measuring Point 2 (Boundary B) 


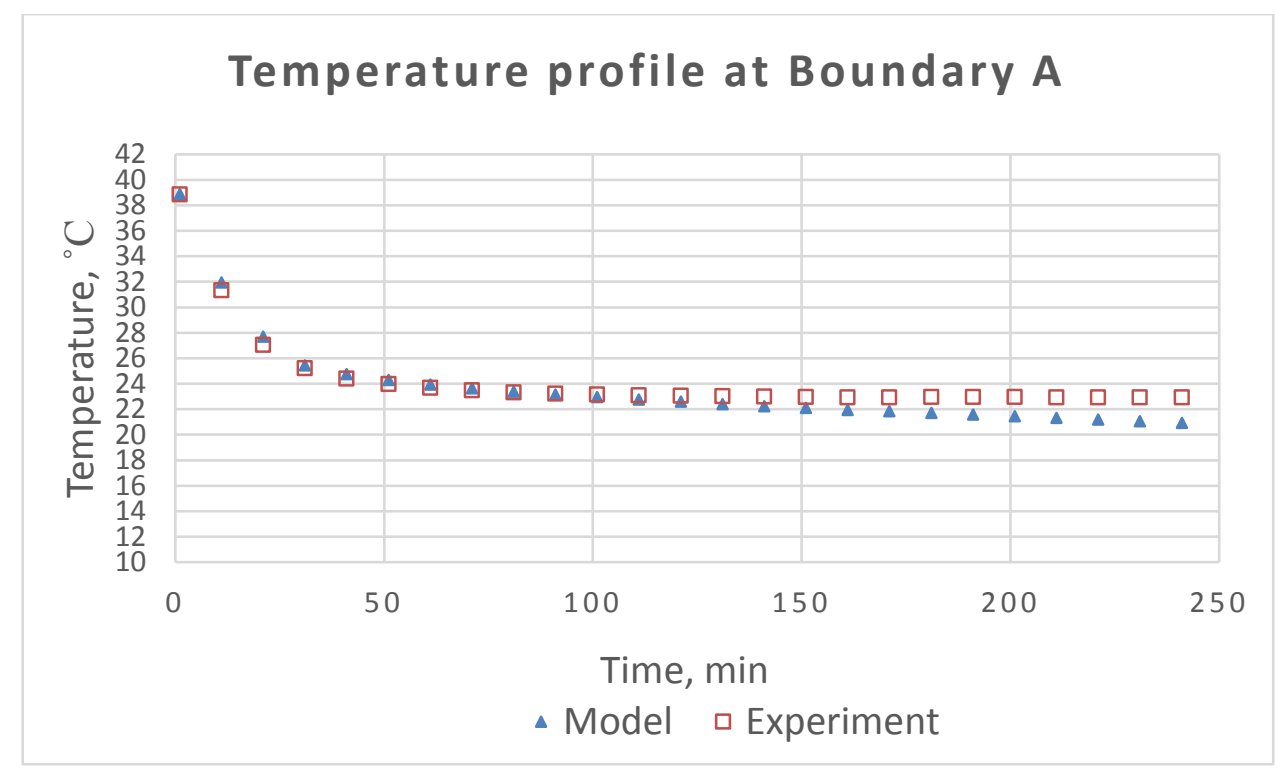

Fig 16. Validation results for Measuring Point 5 (Boundary A)

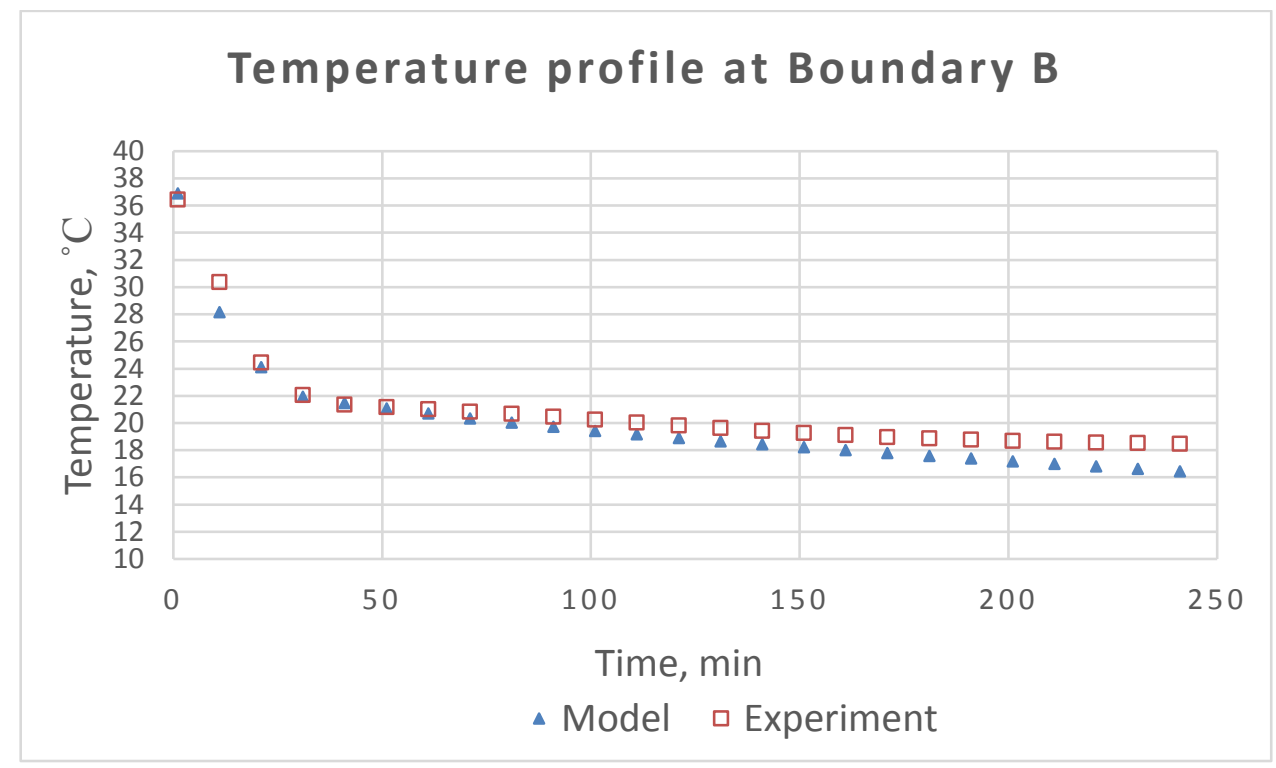

Fig 17. Validation results for Measuring Point 5 (Boundary B)

Good agreement between modelling and experimental data can be observed in the CT-PCM experiment (Fig.(14)-Fig.(17)). This shows that regardless of the experiment conditions, the model is able to predict the thermal behaviour of CT-PCM system. On the other hand, the use uniform cooling power, $\mathrm{q}_{\mathrm{w}}$ for modelling is dependent on the flow-rate of the CT. At high flow rate above $800 \mathrm{ml} / \mathrm{min}$, uniform $\mathrm{q}_{\mathrm{w}}$ can be used in the modelling. Conversely, at low flow rate below $500 \mathrm{ml} / \mathrm{min}$, correction factor needs to be applied to $\mathrm{q}_{\mathrm{w}}$ for accurate modelling. The temperature profile shows that PCM in its liquid state at $30^{\circ} \mathrm{C}$ undergoes a cooling process where solidification (freezing) occurs between $22^{\circ} \mathrm{C}$ to $18^{\circ} \mathrm{C}$. Gradual cooling can be observed during this period where heat is discharge slowly due to the 
presence of sensible and latent thermal storage of PCM. When PCM is completely solid, only sensible energy presents.

\subsection{Limitations}

There are, however, some constraints which may affect the accuracy of the model developed in the study. The PCM is in the form of powder, uneven thickness throughout the panel is one of the biggest challenges to solve in the work.

\section{Conclusion}

The paper presents a novel system of Capillary Tubes embedded in a Phase Change Material (CTPCM) as part of active building environmental design for energy conservation and the improvement of indoor thermal environment. To understand the dynamic thermal characteristics of the CT-PCM system, both numerical and experimental studies are carried out. A set of experiment was conducted by varying the supplying water flow rate and temperature, and the full charging and discharging cycle of PCM was obtained.

A simplified numerical model for CT-PCM system (assuming uniform distribution of temperature on the 2D panel) is developed to allow the parametrical study of the system. The numerical simulation results agree well with the experimental data when the flow rate of the thermal fluid is more than 800 $(\mathrm{ml} / \mathrm{min})$, however, larger discrepancy occurs when the flow rate is smaller than $500 \mathrm{ml} / \mathrm{min}$. Furthermore, a series of correction factors are derived to address such discrepancy in the same time maintaining the benefit of computational efficiency. The proposed approach is limited in scope (this is a 3D heat transfer problem in nature) but particularly promising to integrate with building energy simulation model to understand the energy saving potential at the strategical system design stage.

The model can be used as a quick tool to test the energy saving potential of such CT-PCM system in different climates such as in China.

\section{Acknowledgement}

The authors would like to thank the financial support from the Ministry of Science and Technology for the international collaboration project 'Key Technologies for Terminal Distributed Heating Systems in Yangtze River Basin' (No. 2014DFA62970). This work is associated and supported by the UK-China collaborative research project 'Low carbon climate-responsive Heating and Cooling of Cities (LoHCool)' [EPSRC Grant No. EP/N009797/1] [NSFC Grant No. 51561135002]. 


\section{Reference:}

[1] I. B. Kilkis, S. S. Sager, and M. Uludag, "A simplified model for radiant heating and cooling panels," Simul. Pract. Theory, vol. 2, no. 2, pp. 61-76, 1994.

[2] A. Laouadi, "Development of a radiant heating and cooling model for building energy simulation software," Build. Environ., vol. 39, no. 4, pp. 421-431, 2004.

[3] H. E. Feustel and C. Stetiu, "Hydronic radiant cooling—preliminary assessment," Energy Build., vol. 22, no. 3, pp. 193-205, 1995.

[4] J. Miriel, L. Serres, and A. Trombe, "Radiant ceiling panel heating-cooling systems: Experimental and simulated study of the performances, thermal comfort and energy consumptions," Appl. Therm. Eng., vol. 22, no. 16, pp. 1861-1873, 2002.

[5] B. Lehmann, V. Dorer, M. Gwerder, F. Renggli, and J. Tödtli, “Thermally activated building systems (TABS): Energy efficiency as a function of control strategy, hydronic circuit topology and (cold) generation system," Appl. Energy, vol. 88, no. 1, pp. 180-191, Jan. 2011.

[6] B. W. Olesen, M. De Carli, M. Scarpa, and M. Koschenz, "Dynamic Evaluation of the Cooling Capacity of Thermo-Active Building Systems.," ASHRAE Trans., vol. 112, no. 1, 2006.

[7] K.-N. Rhee and K. W. Kim, "A 50 year review of basic and applied research in radiant heating and cooling systems for the built environment,” Build. Environ., vol. 91, pp. 166-190, 2015.

[8] B. W. Olesen, "Radiant heating and cooling by embedded water-based systems," in Proceedings of I Congreso Climatizacion Eficiente, 2011, p. 4.

[9] X. Xu, S. Wang, J. Wang, and F. Xiao, “Active pipe-embedded structures in buildings for utilizing low-grade energy sources: a review," Energy Build., vol. 42, no. 10, pp. 1567-1581, 2010.

[10] P. Raftery, K. H. Lee, T. Webster, and F. Bauman, "Performance analysis of an integrated UFAD and radiant hydronic slab system,” Appl. Energy, vol. 90, no. 1, pp. 250-257, 2012.

[11] L. F. Cabeza, C. Castellón, M. Nogués, M. Medrano, R. Leppers, and O. Zubillaga, "Use of microencapsulated PCM in concrete walls for energy savings," Energy Build., vol. 39, no. 2, pp. 113-119, 2007.

[12] C. Chen, H. Guo, Y. Liu, H. Yue, and C. Wang, "A new kind of phase change material (PCM) for energy-storing wallboard,” Energy Build., vol. 40, no. 5, pp. 882-890, 2008.

[13] L. F. Cabeza, C. Castellón, M. Nogués, M. Medrano, R. Leppers, and O. Zubillaga, "Use of microencapsulated PCM in concrete walls for energy savings," Energy Build., vol. 39, no. 2, pp. 113-119, Feb. 2007. 
[14] A. M. Khudhair and M. M. Farid, "A review on energy conservation in building applications with thermal storage by latent heat using phase change materials," Energy Convers. Manag., vol. 45, pp. 263-275, 2004.

[15] M. Koschenz and B. Lehmann, "Development of a thermally activated ceiling panel with PCM for application in lightweight and retrofitted buildings," Energy Build., vol. 36, no. 6, pp. 567578, Jun. 2004.

[16] M. Pomianowski, P. Heiselberg, and Y. Zhang, "Review of thermal energy storage technologies based on PCM application in buildings," Energy Build., vol. 67, pp. 56-69, 2013.

[17] N. Soares, J. J. Costa, A. R. Gaspar, and P. Santos, "Review of passive PCM latent heat thermal energy storage systems towards buildings' energy efficiency," Energy Build., vol. 59, pp. 82-103, 2013.

[18] K. Lin, Y. Zhang, H. Di, and R. Yang, "Study of an electrical heating system with ductless air supply and shape-stabilized PCM for thermal storage," Energy Convers. Manag., vol. 48, no. 7, pp. 2016-2024, Jul. 2007.

[19] K. Lin, Y. Zhang, X. Xu, H. Di, R. Yang, and P. Qin, "Experimental study of under-floor electric heating system with shape-stabilized PCM plates," Energy Build., vol. 37, no. 3, pp. 215-220, Mar. 2005.

[20] J. Mazo, M. Delgado, J. M. Marin, and B. Zalba, "Modeling a radiant floor system with Phase Change Material (PCM) integrated into a building simulation tool: Analysis of a case study of a floor heating system coupled to a heat pump," Energy Build., vol. 47, pp. 458-466, 2012.

[21] R. Ansuini, R. Larghetti, A. Giretti, and M. Lemma, "Radiant floors integrated with PCM for indoor temperature control," Energy Build., vol. 43, no. 11, pp. 3019-3026, 2011.

[22] E. Baskin, "Evaluation of Hydronic Forced-Air and Radiant Slab Heating and Cooling Systems.," ASHRAE Trans., vol. 111, no. 1, 2005.

[23] G. Florides and S. Kalogirou, "Ground heat exchangers-A review of systems, models and applications," Renew. energy, vol. 32, no. 15, pp. 2461-2478, 2007.

[24] T. Mikeska and S. Svendsen, "Study of thermal performance of capillary micro tubes integrated into the building sandwich element made of high performance concrete," Appl. Therm. Eng., vol. 52, no. 2, pp. 576-584, Apr. 2013.

[25] Y. Dutil, D. R. Rousse, N. Ben Salah, S. Lassue, and L. Zalewski, "A review on phase-change materials: Mathematical modeling and simulations," Renew. Sustain. Energy Rev., vol. 15, no. 1, pp. 112-130, Jan. 2011. 
[26] C. K. Halford and R. F. Boehm, "Modeling of phase change material peak load shifting," Energy Build., vol. 39, no. 3, pp. 298-305, Mar. 2007.

[27] M. a. Izquierdo-Barrientos, J. F. Belmonte, D. Rodríguez-Sánchez, a. E. Molina, and J. a. Almendros-Ibáñez, "A numerical study of external building walls containing phase change materials (PCM)," Appl. Therm. Eng., vol. 47, pp. 73-85, Dec. 2012.

[28] P. Lamberg, R. Lehtiniemi, and A.-M. Henell, "Numerical and experimental investigation of melting and freezing processes in phase change material storage," Int. J. Therm. Sci., vol. 43, no. 3, pp. 277-287, Mar. 2004.

[29] B. Zivkovic and I. Fujii, "an Analysis of Isothermal Phase Change of Phase Change," vol. 70, no. 1, pp. 51-61, 2001.

[30] C. Yang and P. K. Bansal, "Numerical investigation of capillary tube-suction line heat exchanger performance," Appl. Therm. Eng., vol. 25, no. 13, pp. 2014-2028, 2005.

[31] S. N. Al-Saadi and Z. (John) Zhai, "Systematic evaluation of mathematical methods and numerical schemes for modeling PCM-enhanced building enclosure," Energy Build., vol. 92, pp. 374-388, Apr. 2015. 
APPENDIX 1

Validation results for Measuring Point 2

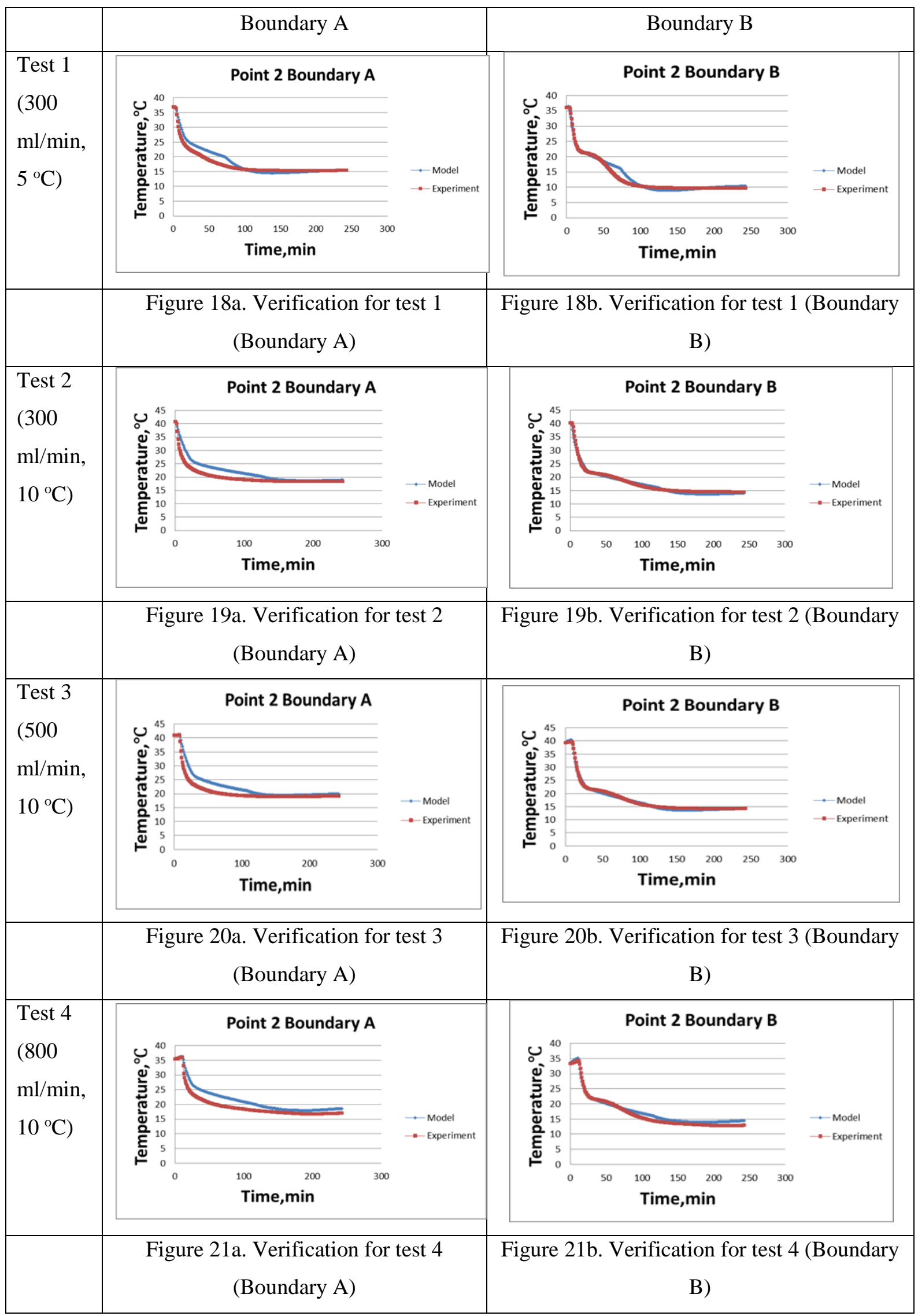




\begin{tabular}{|c|c|c|c|c|c|}
\hline $\begin{array}{l}\text { Test } 5 \\
(1000 \\
\mathrm{ml} / \mathrm{min}, \\
\left.15^{\circ} \mathrm{C}\right)\end{array}$ & \multicolumn{2}{|c|}{ 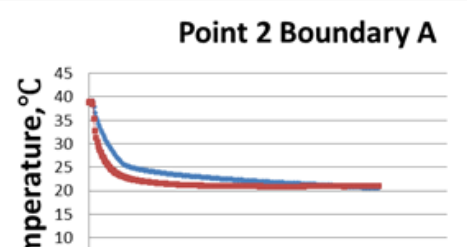 } & $\begin{array}{l}\rightarrow \text { Model } \\
\rightarrow \text { - Experiment }\end{array}$ & 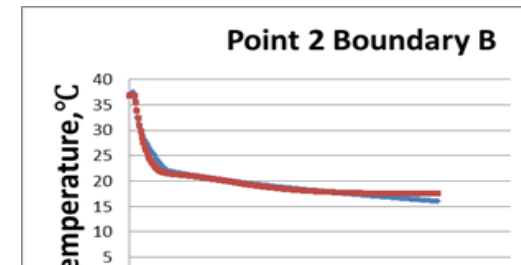 & $\underset{- \text { Model }}{\rightarrow \text { Experiment }}$ \\
\hline & Figur & $\begin{array}{l}\text { 22a. Verification for } t \\
\text { (Boundary A) }\end{array}$ & & $\begin{array}{l}\text { Figure } 22 \mathrm{~b} . \text { Verification for test } 5 \\
\text { B) }\end{array}$ & (Boundary \\
\hline
\end{tabular}

\section{Validation results for Measuring Point 5}

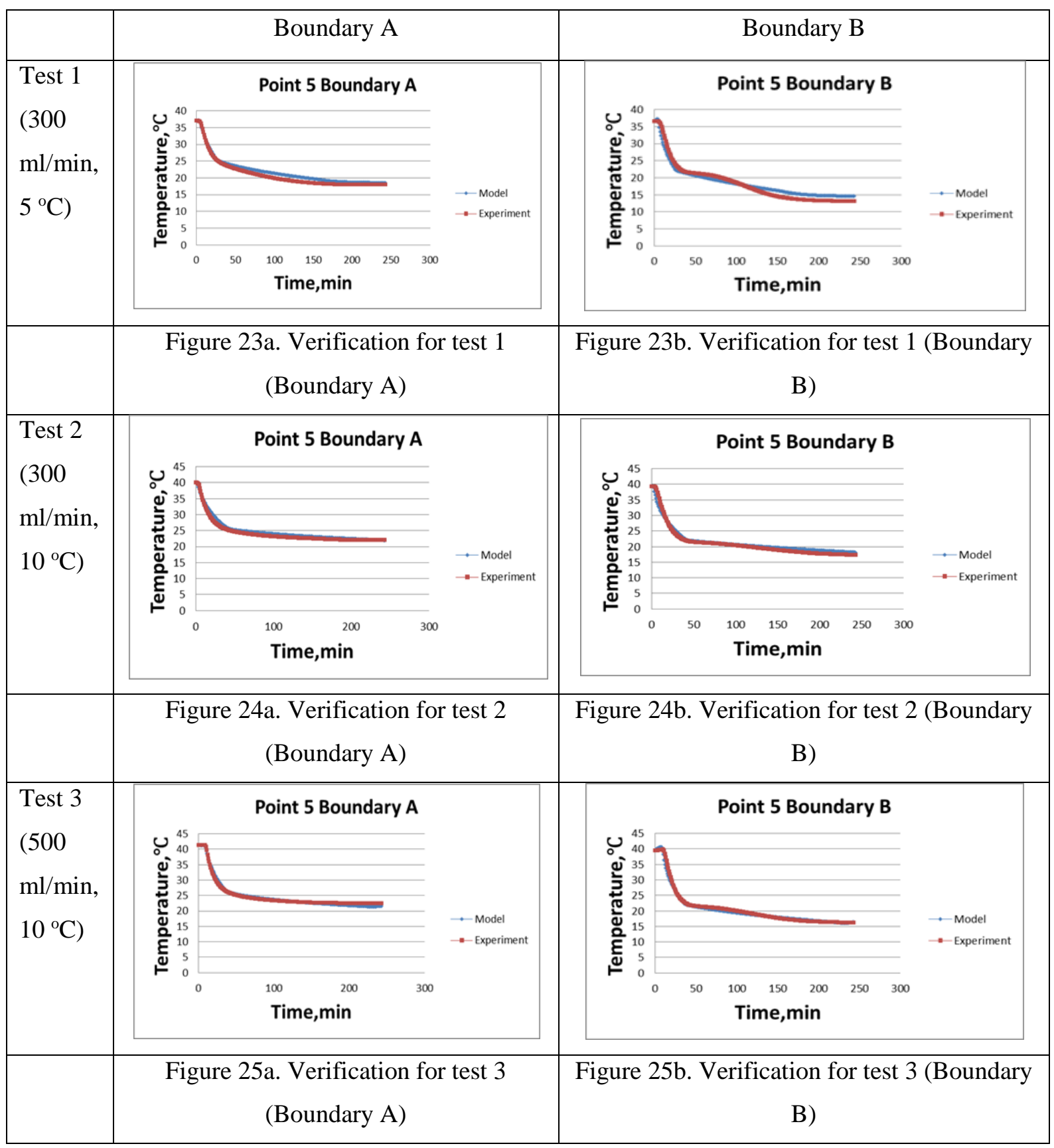




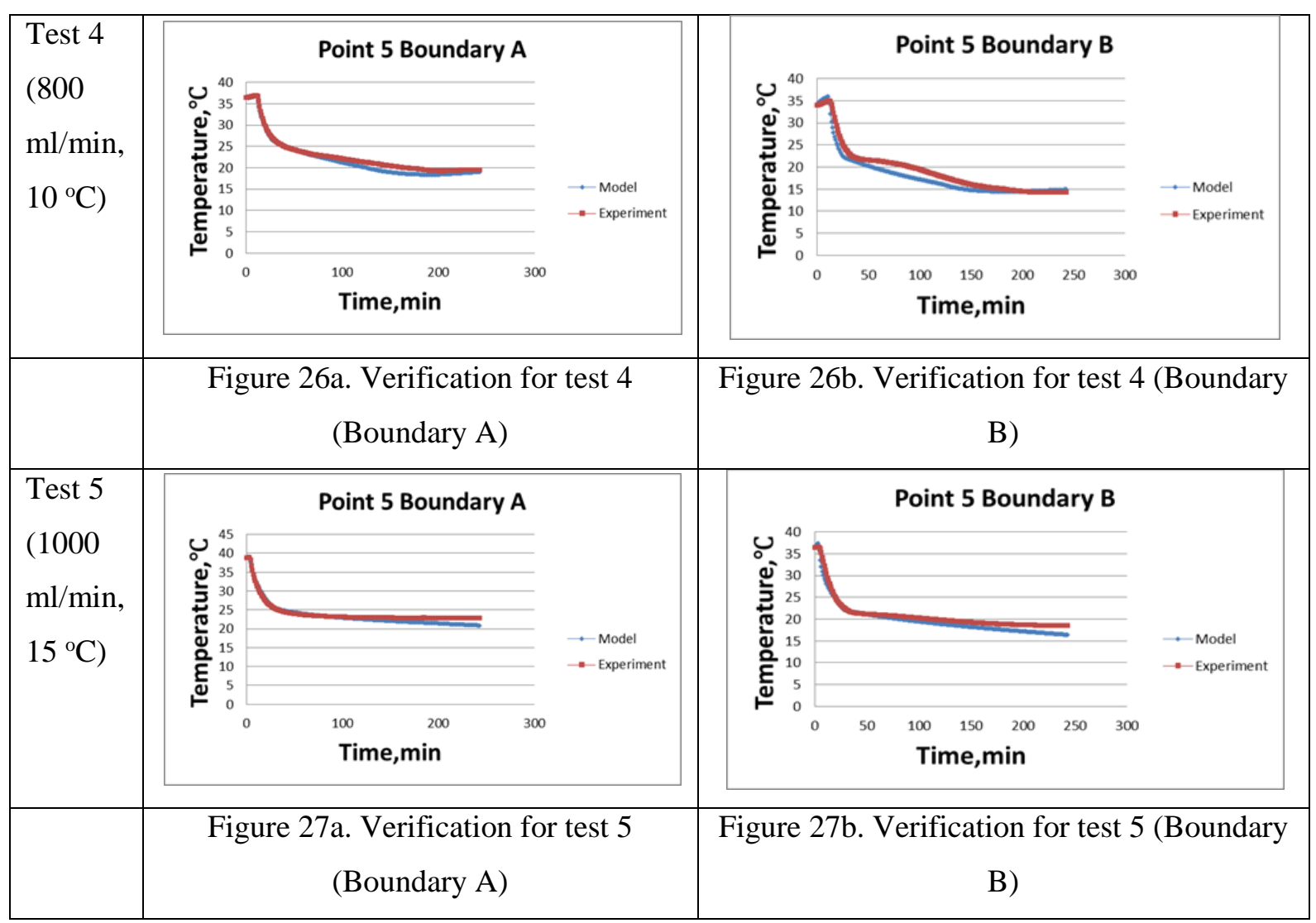

